\title{
PODER, NEGOCIOS Y DESTRUCCIÓN LOS APAGONES DE VENEZUELA EN MARZO DE 2019 Y LA CARTELIZACIÓN DEL ESTADO*
}

\author{
Rogelio Altez \\ Escuela de Antropología, Universidad Central de Venezuela, Venezuela
}

\begin{abstract}
Resumen: Los apagones ocurridos en Venezuela en marzo de 2019 no son una eventualidad, sino una condición producida por relaciones de poder cuyo objetivo no parece enfocarse en el bienestar de la sociedad que representa. El significado de estas circunstancias subyace a esas relaciones de poder y exhibe sus intereses. En el caso de Venezuela, el proyecto socialista comenzó a materializar sus objetivos, precisamente, partiendo de la destrucción del modelo liberal que derrotó, y transformando las formas de enriquecimiento existentes. Para ello desplegó una estrategia de cartelización del Estado, cuyos efectos han sido devastadores para la sociedad entera. La destrucción del Sistema Eléctrico Nacional resulta característico al respecto, y es el ejemplo que permite a este trabajo analizar el problema. Para ello, esta investigación revisa el contexto en el que se transformaron las relaciones de poder en Venezuela a partir de
\end{abstract}

\footnotetext{
Rogelio Altez es antropólogo e historiador. Profesor Titular de la Escuela de Antropología, Universidad Central de Venezuela y Doctor en Historia por la Universidad de Sevilla, España. Especialista en antropología política y en antropología de los desastres. Email: ryaltez@yahoo.es.

* Este trabajo fue realizado durante una estancia como profesor invitado en el Departamento de Historia y Ciencias Sociales (Facultad de Artes Liberales, Universidad Adolfo Ibáñez, Santiago de Chile), en el segundo semestre de 2019. El autor agradece al proyecto Fondecyt 1190265 y las observaciones alcanzadas por los evaluadores del trabajo, pues gracias a ellas ha podido enriquecer su contenido.
} 
1999, así como los efectos de dicha transformación en las formas de hacer negocios y de enriquecerse desde el Estado. Se propone aquí una definición sobre cartelización y una descripción detallada del caso, cerrando con reflexiones que envuelven analíticamente la interpretación de dicho proceso.

Palabras clave: Venezuela, cartelización, relaciones de poder, redes de corrupción y criminalidad, Estado

RECIBIDO: mayo 2019 / ACEPTADO: agosto 2019

\section{POWER, BUSINESS AND DESTRUCTION. VENEZUELA'S 2019 BLACKOUTS AND THE CARTELIZATION OF THE STATE}

ABSTRACT: The blackouts that occurred in Venezuela in March 2019 were not eventualities, rather were events caused by power relations whose goal does not seem to focus on the welfare of the society it represents. The meaning of these circumstances underlies such power relations and evidences their interests. In the case of Venezuela, the socialist project began to attain its objectives, precisely, starting with the destruction of the liberal model that it had defeated, and transforming existing forms of enrichment. To achieve this, it implemented a strategy of cartelization of the State which has had devastating effects on society as a whole. The destruction of the National Electric System is characteristic in this regard, and is the example that allows this work to analyze the problem. To do this, this research reviews the context in which power relations have been transformed in Venezuela since 1999, as well as the effects of such transformation on the ways of doing business and enrichment through the State, offering a definition on cartelization as well as a detailed description of the case, ending with reflections that analytically involve the interpretation of said process.

KeYwords: Venezuela, cartelization, power relations, corruption and crime networks, State

Received: May 2019 / AcCePted: August 2019 
Lo malo de cualquier actividad parasitaria es que no puede durar eternamente. Más tarde o más temprano, según la consistencia de los tesoros acumulados por las víctimas y la eficiencia de los depredadores, las víctimas son despojadas de todos sus bienes y a los ladrones ya no les queda nada que hacer. Carlo M. Cipolla, La odisea de la plata española. Conquistadores, piratas y mercaderes. ${ }^{1}$

\section{LA REORIENTACIÓN DE LAS RELACIONES DE PODER EN VENEZUELA}

i el socialismo bolivariano instaurado desde 1999 debe leerse
veinte años después a través de ocho dígitos de hiperinflación, más de cuatro millones de desplazados, o con una producción petrolera que registra las cifras más bajas en setenta años, algo debe haber ocurrido en el manejo del Estado venezolano. A pesar de este cuadro, en tiempos de Chávez (1999-2012) se registraron los ingresos más altos por venta de crudo en la historia del país. La desaparición de esa riqueza, así como la paralización económica general, no pueden explicarse por errores en la administración o por falta de experiencia, sino por estrategias deliberadas de aprovechamiento ilícito, o bien, por formas novedosas y depuradas de utilizar las instituciones y empresas del Estado con ese fin. Lo que sucede en Venezuela es un proceso sui generis de 'redes de corrupción' y 'redes de criminalidad' que se entrelazan entre sí y a su vez con otras redes, tanto a escala global como regional, y especialmente a nivel nacional. ${ }^{2}$ No obstante, el significado de todo esto se encuentra mucho más allá de conductas reprochables y merece ser comprendido como un proceso de intereses entramado en el poder, responsable de las condiciones catastróficas que hoy resultan inocultables al mundo entero.

Pocos días antes del apagón nacional ocurrido el 7 de marzo de 2019, Venezuela cumplía veinte años de gobiernos bolivarianos ininterumpidos, conformados por los mismos liderazgos desde su inicio. El 'socialismo del siglo XXI', tal como Chávez denominó a ese proyecto

\footnotetext{
${ }^{1}$ Cipolla se refiere al proceso de explotación española en las primeras décadas del siglo XVI.

${ }^{2}$ Las categorías de redes de corrupción y redes de criminalidad las hemos tomado de Mascareño et al. $(2016,685)$.
} 
político, se instauró en el poder luego de derrotar por la vía electoral al modelo liberal bipartidista de cuarenta años de duración y representante de una democracia sostenida que Venezuela nunca antes había disfrutado. ${ }^{3}$ La crisis de ese bipartidismo, aflorada con los estallidos sociales de 1989, acelerada por decisiones macroeconómicas calamitosas y protagonizada por una debacle política estructural hasta su derrota en 1998, fue capitalizada hábilmente por el movimiento chavista bajo el lema 'Ahora le toca al pueblo'. Tal expresión representaba el señalamiento crítico hacia la corrupción que identificó a los gobiernos anteriores y sintetizaba la defensa moral de un porvenir con 'justicia social'. ${ }^{4}$

\footnotetext{
${ }^{3}$ La historia de los gobiernos de Venezuela, desde su independencia hasta el presente, enseña una significativa mayoría de presidentes militares y gobiernos despóticos o dictatoriales. Solo se cuenta como democracia el período que, precisamente, se inicia con la derrota de la última dictadura militar liderada por el general Marcos Pérez Jiménez (en el poder desde 1948, a partir del derrocamiento de Rómulo Gallegos, hasta 1958, cuando cae por un golpe de Estado). Antes de esto no existió en el país ningún gobierno democrático (real o estable) ni mucho menos liberal (en el sentido contemporáneo del término). La caída de Pérez Jiménez, cuyo período disfrutó de altos ingresos petroleros y una importante bonanza económica, representó la victoria política de sectores con intereses marcados en otras formas de hacer negocios, enfocados en un modelo democrático liderado por elites abiertas a la flexibilización política, y concentradas en la unidad nacional como objetivo ideológico. El pacto político de 1958, alianza entre partidos de orientación democrática, capital privado, militares de perfil institucional, la Iglesia católica y los sectores profesional e intelectual, devino en la democracia liberal que dio continuidad a los vínculos históricos con el capital estadounidense, ahora asentados sobre formas de contratación y asociación basadas en la libre competencia y en la apertura comercial. Sobre el proceso de surgimiento de esta democracia y del Estado liberal en Venezuela, así como acerca del proceso de deterioro de su eficacia, ver Coronil (2002). Desde nuestro punto de vista, pensamos que la democracia liberal contribuyó decididamente con el desarrollo de la clase media en Venezuela, estrato social que no existía antes de ese proceso. Asimismo, condujo a la consolidación de una clase política que, en su propio detrimento, muy pronto naturalizó su lugar en el poder y abandonó el trabajo con sus bases electorales.

${ }^{4}$ La democracia liberal en Venezuela garantizó, además de una serie de gobiernos favorables a la negociación política como ética de poder, la restricción a los partidos y movimientos de izquierda en la participación en el pacto político de 1958. Fue un efecto de los acuerdos originales cuya tendencia había sido la consolidación de los negocios con Estado Unidos y la desafectación de las ideas radicales que optaban por otras propuestas. La naturalización de este pacto como un statu quo de la sociedad venezolana y la boyante situación económica determinada por los ingresos petroleros de la década de 1970, devinieron, entre otras cosas, en populismos despilfarradores y en la corrupción de las funciones del Estado. Cuando la deuda pública y la crisis institucional alcanzó a Venezuela a finales de la década de 1980, los 'grandes virajes' (como proclamaba el plan de gobierno de Carlos Andrés Pérez en 1989) que desplegaron medidas económicas
} 
Como muchos otros países de América Latina, las decisiones para resolver la fuerte crisis institucional y los embates de la deuda externa en Venezuela al final de la década de 1980, llegaron en forma de medidas abruptas y basadas en la confianza de sus efectos a largo plazo, desatendiendo el impacto inmediato que habrían de tener, ciertamente, en las políticas públicas de beneficio social que abanderaron a los gobiernos populistas y despilfarradores anteriores. El favorecimiento a los sectores privados, la privatización de buena parte de los servicios que estaban en manos del Estado y, sobre todo, la autonomización de las industrias que han sido la base del rentismo venezolano (petróleo, petroquímica y minería), condujeron a una crisis aún mayor, especialmente reflejada en la desarticulación de los partidos políticos tradicionales, en la progresiva ineficiencia de las instituciones del Estado y en un efecto recesivo sobre la economía nacional. Todos estos aspectos fueron indicadores insoslayables del colapso estructural del modelo liberal en Venezuela, base y estímulo de una propuesta política radical que se llevaría por delante el statu quo naturalizado por la clase política gobernante a la vuelta de cuatro décadas. ${ }^{5}$

La propuesta de Chávez, es decir, la alternativa radical que surgió de aquella crisis, fue la de una revolución: un proyecto que se plantea destruir el modelo que derrota por no hallar allí el reflejo de sus intereses políticos, materiales ni ideológicos, con el objeto de levantar un modelo

abruptas en favor del capital privado y por encima de las políticas sociales, cristalizaron en el Caracazo de febrero-marzo de 1989, un estallido social de consecuencias catastróficas. Para un repaso de este proceso, recomendamos el trabajo de Margarita López Maya (2005). El Caracazo será, sin lugar a dudas, la plataforma mítica y el imaginario colectivo al que acudirá la izquierda bolivariana como referente histórico y fundacional de su propuesta revolucionaria. Los hechos de ese contexto serán tan decisivos en la crisis política liberal como en el surgimiento y consolidación del proyecto socialista liderado por Chávez.

${ }^{5}$ Sobre las medidas 'neoliberales' en América Latina, ver Ramos (1997). Sobre el efecto político de esas medidas en Venezuela, ver Romero (1994) y Arenas (2001). Con todo, las causas de la conformación del chavismo y su llegada al poder no pueden adjudicarse únicamente a estas medidas, pues el neoliberalismo "no es el único culpable" (Corrales y Penfold 2012, 17). Antes bien, un conjunto de problemas contribuyó directamente con la debacle del modelo anterior: la inestabilidad macroeconómica por la persistente dependencia de la exportación petrolera; la fragmentación de los partidos políticos; la contracción económica de la década de 1990 por errores cometidos desde el gobierno; "y la crisis asiática de 1997, la cual arrasó la economía venezolana justo en momentos de la campaña presidencial de Chávez" (Corrales y Penfold 2012, 17). 
que sí los satisfaga. ${ }^{6}$ La derrota de los intereses depuestos, precisamente, supone la neutralización de sus agentes y su alejamiento de las relaciones de poder, así como también la construcción de otros entramados y reglas de juego donde los nuevos objetivos puedan lograrse garantizando el extrañamiento perpetuo de las clases que, en el modelo anterior, se habían asegurado de que estos sectores ahora victoriosos no participaran del reparto de las riquezas. Si acaso lograban alguna participación, lo hacían en el extremo más alejado del circuito de relaciones clientelares que favorecía la reproducción del modelo, y no su sustitución.

El bloque que ganó las elecciones en 1999 sumaba, desde luego, clases antes desfavorecidas, desplazadas de los beneficios que se habían asegurado para sí aquellos que construyeron la democracia liberal gobernante desde 1958. Los negocios existentes hasta entonces suponían una forma de circulación de capital ciertamente liberal, cuyos circuitos se movían hacia dentro y hacia fuera en entramados nacionales e internacionales que giraban con ese sentido, tanto económico como ideológico. Intereses antagónicos no podrían reproducir ni sostener negocios en esa dirección, pues con ello prolongarían la vida de sus competidores. La revolución debía garantizar un acceso diferente a la riqueza, y así lo hizo.

La transformación de las reglas de juego fue igualmente estructural. Se cambiaron las leyes, desde luego, pero también fueron modificadas las instituciones y sustituidos los socios de todos los negocios, incluidos los internacionales. Con ello cambiaron, asimismo, las formas de negociación, ahora enfocadas en la eliminación de competidores, tanto los antiguos liberales como los emergentes que no se acoplaran a la satisfacción de los nuevos objetivos y a la circulación del capital impuesta desde el Estado. En esa transformación de los negocios y especialmente de las formas de llevarlos a cabo, el socialismo bolivariano se desenvolvió sobre la base de estrategias de control y exclusión de competidores en casi todos los espacios de acceso a la riqueza, a semejanza de los carteles que operan en la ilegalidad, pero con la institucionalidad del Estado como su aparato. Esto, que desarrollaremos más adelante, supone la conversión del Estado en una fuente de riquezas excluyente que funciona como plataforma de negocios a modo de cartel o como holding de carteles. El despliegue de estas nuevas estrategias no solo operó hacia dentro del país, sino también hacia fuera, lo que representó

${ }^{6}$ Hemos trabajado el concepto de revolución en ocasiones anteriores (Altez 2012, 2015). 
nuevas sociedades económicas dispuestas a hacer negocios en los mismos planos o a establecer relaciones sin objetar la ética que al respecto se desarrollaba desde Venezuela.

Los socios internacionales que aparecieron en acción, por supuesto, debían ser igualmente antagónicos a los circuitos liberales de riqueza cuyo vigor, en planos geoestratégicos, había sido impulsado por el protagonismo de intereses estadounidenses, asentados en Venezuela desde un siglo atrás. Derrotar estos intereses, cambiar los circuitos de capital y sostener un modelo suficientemente sólido como para impedir el retorno de los adversarios, necesitó de socios robustos, capaces de hacer frente a bloques económicos que no solo operaban en niveles nacionales, sino regionales y globales.

Esto condujo, inexorablemente, a asociarse con Rusia y China, los competidores más contundentes de Estados Unidos de América. La aproximación a estas potencias supuso, a su vez, una escala estratégica en Cuba, el nexo geopolítico que Chávez desarrolló apenas alcanzó la presidencia. ${ }^{7}$ Desde entonces, Venezuela giró su disposición geoestratégica hacia esas latitudes, derroteros que representaron no solo un viraje antagónico con relación a los intereses anteriores, sino también nuevas formas de hacer negocios que debían comenzar por reconocer políticamente otros contenidos ideológicos, otros valores, otra moral. La revolución fue la plataforma de estos cambios.

La relación costo-beneficio de estas nuevas sociedades pronto se haría notar. Por un lado, la fractura de los vínculos históricos con

\footnotetext{
${ }^{7}$ Ya en 1999, el primer año de gobierno de Chávez, Venezuela contó con médicos cubanos desplegados en comunidades y localidades alejadas de los servicios de salud metropolitanos. Este fue uno de los indicadores tempranos del sólido vínculo que el militar venezolano había establecido con sus símiles al mando de Cuba; quizás pueda decirse, igualmente, que esta temprana presencia de personal cubano en Venezuela es evidencia de la anterioridad del vínculo entre Chávez y Cuba, muy probablemente, lo que podría leerse como parte de un proyecto político y económico menos pragmático y de objetivos mayores a los de una relación bilateral. Más tarde, con las transformaciones propias del socialismo de Chávez, los médicos cubanos jugaron un papel importante en la implementación del nuevo modelo de asistencia sanitaria que el mandatario denominó Misión Barrio Adentro, y que consistió en la instalación de pequeños módulos de atención gratuita en zonas populares con la presencia de los médicos provenientes de la isla. La avanzada de los médicos cubanos significó la primera contraprestación por parte de Cuba ante el apoyo político y material que recibe de Venezuela a partir de la llegada de Chávez al poder. En adelante, estos médicos, generalmente de rotación bianual, alcanzarán a sustituir a muchos profesionales venezolanos en cargos públicos al respecto, recurso utilizado con objetivos políticos y como garantía institucional de las decisiones de Estado en el área.
} 
socios norteamericanos impactó directamente sobre el capital empresarial venezolano, identificado como el representante más conspicuo de la ideología liberal. El viraje geoestratégico interrumpió los circuitos de esas relaciones, desviando el capital hacia otros agentes que debían estar dispuestos a contratar con nuevos socios y, sobre todo, nuevas formas de contratación. A esto se sumó el control oficial de las divisas desde 2003, lo que apartó al capital tradicional del libre acceso a las importaciones, garantizando el manejo diferencial, y sobre todo discrecional, de las monedas fuertes. El resultado fue, especialmente, el debilitamiento del capital tradicional, la quiebra de empresas privadas, la reducción del aparato productivo y el fortalecimiento de los circuitos estatales de capital, cuyo destino de enriquecimiento cambiaba de manos y de socios.

La sociedad con chinos y rusos, básicamente, representó la cristalización de los nuevos intereses. Simboliza la relación geopolítica que se articula con la retórica socialista, enrostra a los liberales la posibilidad de convivir con potencias mundiales diferentes y antagónicas a los estadounidenses, y abre la posibilidad de enriquecimiento a nuevas firmas, empresas y capitales dispuestos a proyectar los nuevos valores y morales. En correspondencia con la crítica a la ética liberal, las nuevas formas de enriquecimiento no podrían materializar 'estados de bienestar' ni 'calidades de vida'; solo reprodujeron la pobreza y crearon nuevos ricos.

Sobre los capitales quebrados, rematados o directamente abandonados, avanzaron los nuevos socios del Estado, militantes del socialismo y fieles al mando, agentes del mismo clientelismo histórico con nuevos operadores, y sustitutos del consumo suntuario, antes reservado para las clases media y alta venezolanas. Más aferrados al enriquecimiento y a ese consumo, los nuevos ricos bolivarianos hicieron honor a la doctrina antiliberal y construyeron un mundo de relaciones económicas antagónico, basado en el Estado como plataforma de los negocios, y con acceso controlado y excluyente a los mercados.

Sobre la base de estos planteamientos, nos proponemos analizar las nuevas estrategias de negocios que el Estado bolivariano construyó en forma de cartelización para el acceso y control de la riqueza en Venezuela, tomando como ejemplo el colapso del Sistema Eléctrico Nacional (SEN), que tuvo lugar en marzo de 2019. A partir de la reconstrucción del proceso de aprovechamiento excluyente de los negocios vinculados con el servicio eléctrico, interpretaremos la destrucción del mismo como un 
efecto de dicho proceso, y como un indicador indefectible de esas nuevas formas de enriquecimiento desplegadas por el modelo socialista liderado por Chávez y continuado por Maduro, formas que se articulan con intereses globales que persiguen igualmente transformar los sentidos tradicionales de circulación de capital en beneficio de importantes competidores antiliberales, ahora robustecidos en el siglo XXI.

Con ese objetivo, en primer lugar, nos aproximaremos a una definición de los carteles como forma de negocios y a su significado en la cartelización del Estado en Venezuela. Luego realizaremos la reconstrucción del proceso de aprovechamiento y destrucción del SEN como efecto de su explotación cartelizada; finalmente, interpretaremos este proceso como parte conformadora de la propuesta socialista bolivariana y su propósito de destrucción del modelo liberal, dentro del contexto político, ideológico y económico del siglo XXI en Venezuela. La proyección interpretativa del caso hacia otros escenarios contemporáneos, asimismo, resulta ineludible a la vuelta de comprenderlo como indicador de un proceso mayor, en el que el sentido liberal en la circulación global del capital parece estar amenazado.

\section{EL ESTADO COMO HOLDING DE CARTELES}

El desplazamiento de los competidores, como objetivo de los nuevos intereses, devino en aniquilación, en correspondencia con los perfiles radicales que enarbolan las revoluciones. El recurso desplegado para lograr estos objetivos en la captura de los negocios tradicionales fue el de la cartelización. No se trata de carteles en el sentido económico del término, como lo es la OPEP, por ejemplo. Estamos en presencia de estrategias que persiguen 'evitar la mutua competencia' a través de la delimitación violenta de sus territorios de acción, garantizando la continuidad de los negocios y el enriquecimiento de los operadores, sin detenerse en la valoración de detrimentos a terceros, aunque se trate de un país entero, como es el caso de Venezuela. ${ }^{8}$

\footnotetext{
${ }^{8}$ Un cartel es una "Organización ilícita vinculada al tráfico de drogas o de armas. Convenio entre empresas similares para evitar la mutua competencia y regular la producción, venta y precios en determinado campo industrial". Hallamos esta definición, tomada del Diccionario de la Real Academia Española, en el trabajo de Carrión y Pinto (2017, 84). Esto se puede complementar con los cuatro atributos que suma Ciro Krauthausen $(1994,113)$.
} 
Esta calificación de 'carteles' proviene de aquellos asociados al narcotráfico con orígenes en Medellín y Cali, hacia los años ochenta del siglo pasado. Propios de mercados y comercios ilegales, su definición va asociada con la delincuencia y la criminalidad. La asociación con el proceso venezolano no es una analogía, sino una adaptación del término a partir de características similares propias de los carteles delictivos, que en el caso del Estado bolivariano operan, como lo mencionamos, de forma sui generis. Estamos ante un modelo de poder sin antecedentes y probablemente sin símiles contemporáneos.

La lógica de los carteles es, asimismo, económica: actúan "entre el poder y el mercado, en razón de su naturaleza simultáneamente empresarial y delictiva" (Palacio y Serrano 2010, 127). ${ }^{9} \mathrm{Su}$ foco en el enriquecimiento personal, como lo destaca Krauthausen (1994), permite establecer una diferencia substancial con términos que no necesariamente son sinónimos. En este caso, 'enriquecimiento' no significa desarrollo económico, ni crecimiento material equitativo o libertad de oportunidades; aquí el enriquecimiento es una meta puntual y específica: representa la captura excluyente de la riqueza para beneficio propio, nada más.

Parte del despliegue delincuencial característico de los carteles no se encuentra asido únicamente a actividades ilegales, sino también a estrategias de control y dominación basadas en la violencia. La eliminación de competidores es, de por sí, violenta, y en el mundo criminal esto se ejecuta de forma literal; en el caso de un Estado cartelizado opera según bases legítimas y formales, garantizadas por el monopolio de las leyes y de las armas. Se trata de formas de violencia de doble articulación, concreta y simbólica, que en los escenarios políticos de una revolución se exacerban en todos los espacios. La cartelización es, al fin y al cabo, una imposición coercitiva, una estrategia de poder que en Venezuela ha adquirido la forma del Estado.

Cartelizar los negocios en la Venezuela socialista ha sido, antes bien, un efecto y no estrictamente una elección. Resulta de la necesidad de construir una plataforma de enriquecimiento y satisfacción de intere-

\footnotetext{
9 “Así, podemos constatar una infinidad de grupos y redes que de alguna manera están involucrados en el negocio, tendencias de centralización representadas en los llamados 'carteles', múltiples y extremas formas de violencia física y un sinfín de nexos las más de las veces corruptores de las autoridades y la sociedad. Quizás el único enfoque analítico para ordenar esta complejidad consiste en una perspectiva de mercado" (Krauthausen 1994, 117).
} 
ses que desplazase a los vigentes, instaurados por más de un siglo en el país, y que además garantizara su alejamiento definitivo de las relaciones de poder. Como lo vimos, la alternativa políticamente antagónica al Estado liberal condujo a asociaciones internacionales estratégicas dispuestas a favorecer la construcción de un entramado capaz de beneficiar esos intereses, al tiempo que sirviese de proyección a los nuevos socios en escenarios globales. Cartelizar al Estado significó desplegar formas violentas de irrupción y control suficientes como para imponer condiciones ante los entramados existentes desde antaño. Otros recursos, más afables y de voluntad política, no podrían ser eficaces para semejante tarea.

Así, la riqueza a capturar se hallaba en el Estado, pero también en las oportunidades que el Estado favorece para todas las formas de enriquecimiento. Los capitales formales, provenientes del petróleo, por ejemplo, o de las industrias privadas y públicas, fueron captados en este proceso a través de estrategias jurídicas impuestas por el gobierno (expropiaciones y nacionalizaciones), o bien, por formas de control excluyentes reservadas al ejercicio institucional (expresadas, entre otras cosas, en el manejo discrecional de los ingresos nacionales). ${ }^{10}$ Junto a la apetencia por los capitales formales se fueron desplegando intereses concentrados en capitales ilícitos, también controlados desde el Estado: tráfico de armas, minería abrasiva, narcotráfico, o la contraprestación de servicios con grupos armados. ${ }^{11}$

\footnotetext{
10 "El control del Estado se ha extendido a una variada gama de industrias, que van desde la electricidad y las telecomunicaciones, hasta sectores ordinarios, como el cemento y los hoteles. Las expropiaciones se han extendido de un puñado de lotes abandonados, a industrias relevantes y altamente rentables" (Corrales y Penfold 2012, 13).

${ }^{11}$ Una relación que combina diversos intereses con diferentes fuentes de riqueza, legal o ilegal, se observa en torno a la explotación del llamado Arco Minero del Orinoco, donde el Estado ha permitido a grupos armados, como el Ejército de Liberación Nacional (ELN) de Colombia, operar libremente en la región a cambio de patrullaje y protección a las operaciones extractivas. En contraprestación, el ELN se ve favorecido al hallarse en un territorio donde quienes lo persiguen no tienen jurisdicción. Grupos como estos, por otro lado, han sido los principales clientes en el tráfico de armas conducido por el Estado en tiempos de Chávez, cuando su gobierno decidió cambiar el parque militar por armas y equipos procedentes de Rusia, principalmente (también de España y China), creando un puente comercial y sirviendo de tercerización al negocio. Del mismo modo, el Estado bolivariano ha creado nexos directos con la delincuencia organizada del país, a cambio de que opere como grupos de presión política, e incluso como cuerpos represivos, tal como sucedió en la coyuntura del ingreso de la Ayuda Humanitaria entre el 22 y el 24 de febrero de 2019
} 
En la violencia característica de la forma de ejecutar los negocios que es propia de los carteles, el Estado socialista venezolano se apoyó, decidida y determinantemente, en las Fuerzas Armadas. Allí, en el estamento del que provino Chávez y sus compañeros de proyecto, subyace el recurso articulador de la cartelización. Los militares juegan un rol fundamental en ello, pues no solo detentan las armas del Estado, sino que bajo su control y fiscalización se encuentran los espacios clave donde tienen lugar buena parte de los negocios: fronteras; aduanas; industrias petrolera, petroquímica y minera; instituciones y servicios públicos. Por otro lado, la propuesta bolivariana representa, en su sentido más conspicuo, una mancomunidad entre militares, izquierda y 'pueblo', una amalgama que no solo ha funcionado política y estratégicamente, sino ideológicamente al mismo tiempo. ${ }^{12}$

Para garantizar la indisputabilidad del acceso a los capitales que se convirtieron en objetivo de los negocios cartelizados, formales o ilícitos, la política del socialismo del siglo XXI puso en práctica recursos que ajustaron la plataforma estatal en beneficio de ello. Por un lado, justificados por la descalificación crítica del Estado liberal y con el objeto de distanciarse de su ética conservadora, se desarrollaron redes paraformales sobre las relaciones institucionales con base en prácticas populistas de convocatoria y organización, ajustadas sobre entramados clientelares y de fidelidad estrictos. Por otro lado, y como un efecto de lo anterior, se conformaron redes de corrupción ancladas a esas instituciones, controladas desde las jerarquías del liderazgo político con circuitos de poder verticales. Este esquema, por lo demás, no se

en la frontera con Brasil, donde un "número indeterminado de indígenas" fue asesinado por grupos armados en forma coordinada con la Guardia Nacional, del mismo modo que en la frontera con Colombia operaron en esa coyuntura otros grupos organizados con presidiarios excarcelados para ese fin. Detalles de estos hechos pueden hallarse en la prensa nacional e internacional, y también en el "Pronunciamiento" del Consejo de la Facultad de Ciencias Económicas y Sociales de la Universidad Central de Venezuela, suscrito el 28 de ese mes en Sesión Extraordinaria.

12 "Los militares están presentes en el gabinete ejecutivo, en el manejo de cada vez más empresas del Estado, y en la administración de programas gubernamentales en las regiones. El chavismo echó para atrás la tendencia observada en América Latina hasta fines de los años noventa, de contener, antes que expandir, el papel de los militares en el gobierno y en el gasto destinado a rubros ajenos a la seguridad nacional" (Corrales y Penfold 2012, 13). 
aleja mucho de otros ejemplos latinoamericanos ${ }^{13}$ sin embargo, en el caso venezolano se desplegaron, en paralelo e igualmente articuladas entre sí, redes de criminalidad que al mismo tiempo soportan, en buena medida, el peso de las violencias concreta y simbólica propias de una revolución. ${ }^{14}$

A esto debe sumarse, con el mismo objetivo de eliminar competidores por las riquezas, la depuración de formas autoritarias de gobierno, enmascaradas en la propuesta de la democracia participativa, que han asegurado, igualmente, la neutralización de la oposición política en Venezuela en un movimiento aparentemente contradictorio: su sostenimiento en el tiempo como el enemigo necesario que justifica la permanencia del acto revolucionario. ${ }^{15}$ Por último, en correspondencia

13 "[S]in necesariamente descartar lo anterior, se podría suponer que en América Latina el tipo de instituciones democráticas que promueven los derechos fundamentales (individualización, universalismo normativo, división del trabajo, diferenciación funcional, Estado de derecho, democracia política) pueden cooperar, pero también competir con u oponerse a formas alternativas de organización social estructuradas en torno a redes informales" (Mascareño et al. 2016, 684).

${ }^{14}$ Son redes paraformales "en el sentido de que, siendo informales, están junto a instituciones formales con las cuales coevolucionan y se integran de manera sinérgica"; las redes de corrupción, "a su vez, se superponen a las instituciones democráticas... [y] utilizan los rendimientos de esas instituciones en su propio beneficio"; las redes de criminalidad, "por su parte, producen un desacoplamiento de las instituciones democráticas y establecen un predominio en un espacio social determinado" (Mascareño et al. 2016, 684). En Venezuela, la criminalidad ha sido amparada por el Estado en forma de grupos de presión y represión, como lo comentamos anteriormente, permitiendo en contraprestación su operación con laxitud. Los trabajos de Roberto Briceño-León son elocuentes en ese sentido; véase del autor, entre otros, "Violencia urbana, sistema normativo y democracia en Venezuela" (2015). El problema de la criminalidad en Venezuela se asemeja a lo que Carrión y Pinto $(2017,83-84)$ comentan al respecto: "el crimen que hoy se lleva a cabo no es ejecutado por una organización que proviene de la suma de personas, sino por la integración de cárteles, mafias o bandas criminales dentro de un sistema articulado de nodos y circuitos, inscrito en una red de redes que asume la figura de una red global del crimen". En correspondencia con el objetivo de captura de riquezas que despliegan los carteles en general, complementamos esto con lo que anota Krauthausen $(1994,113)$ : "con delincuencia organizada nos referimos a grupos o redes que de manera continua se dedican a actividades ilegales que apuntan hacia el enriquecimiento personal".

${ }^{15}$ En los últimos años, el gobierno bolivariano ha inhabilitado o encarcelado a todos los candidatos que potencialmente pueden ser competidores de envergadura en una campaña presidencial o regional. El recurso de actuar bajo plataformas jurídicas con arreglo a fines no es un descubrimiento del socialismo del siglo XXI. Lo que sí resulta una innovación es la argumentación de estos subterfugios, todos basados en un discurso 
con lo anteriormente señalado, la promoción de sociedades económicas internacionales que garanticen una circulación de capital protegida y alejada de sus rivales.

Este entramado estratégico envuelve y potencia los intereses de las nuevas clases de poder venezolanas. Ha sido un proceso progresivo que construyó una forma de hacer negocios cartelizada, y que no se detuvo con la transformación del Estado. Elaboró un complejo entramado de redes, basado en fidelidades y clientelismo, que penetró todos los ámbitos del país, desplegándose también hacia afuera, y operando como carteles controlados desde el Estado. ${ }^{16}$ Así, todos los negocios son administrados en un movimiento centrípeto que absorbe riquezas, por un lado, y centrífugo, por otro lado, eliminando competidores. Para ello el Estado torna en holding de carteles, y a su vez opera "a través de tercerización (subcontratación) y franquicia (modelo que se entrega a un tercero), articulados por circuitos y nodos dispersos territorial y sectorialmente" (Carrión y Pinto 2017, 83).

El socialismo del siglo XXI ha convertido fuentes de riquezas tradicionales y formales - como la industria petrolera, la energía eléctrica o las aduanas portuarias - en negocios cartelizados; pero también ha creado nuevos negocios con las mismas características, como las cajas de comida o el contrabando de combustible. Cada fuente es controlada por redes que se apoyan en el aparato institucional público para operar con legitimidad, marcando con ello una diferencia crítica con las "em-

coincidente con consignas antiimperialistas, socialistas e incluso antiterroristas, en clara demostración del aprendizaje histórico de otros autoritarismos y como depuración de los mecanismos de presión y represión que los Estados totalitarios utilizan en su beneficio. Han sido lo suficientemente hábiles en ese sentido como para lograr una matriz de opinión internacional en su favor, según la cual son víctimas de planes de derrocamiento, golpes de Estado e incluso magnicidios que recurrentemente se perpetran en su contra. Ninguna de las dictaduras del Cono Sur, por ejemplo, o ningún gobierno de larga duración autoproclamado de izquierda, como el de Nicaragua o el de Cuba, alcanzaron un nivel de simpatía internacional tan amplio como el proyecto iniciado por Chávez.

16 "Los intereses particulares de grupos específicos cooptan marcos institucionales determinados y los llevan a operar en beneficio propio" (Hoevel y Mascareño 2016, 47). Este señalamiento crítico describe el objetivo específico del empleo masivo puesto en práctica por el Estado venezolano en tiempos de Chávez, cuando el barril de petróleo superó los cien dólares en el mercado. Así fue como el socialismo bolivariano cooptó fidelidades y compromisos, bajo mecanismos de sujeción clientelares característicos, y de la mano de una complicidad progresiva, según fuese el nivel de responsabilidad que cada cargo representara en las instituciones públicas. 
presas ilegales", que actúan con "atribuciones político-jurídicas" fuera de la ley (Dombois 1998, 17). Buena parte de ese funcionamiento se complementa con una defensa armada de las transacciones, pues a pesar de tener lugar en espacios institucionales, la riqueza movilizada suele producir grandes cantidades de dinero que no son volcadas en ámbitos formales de inversión, sino que recorren circuitos clandestinos hasta su tercerización o lavado. Así, las redes de corrupción se desenvuelven en marcos institucionales paraformales que despliegan actividades criminales como seguro de las transacciones.

La violencia característica de los carteles, por otro lado, no repara en criterios de sostenibilidad; opera con una lógica de depredación sin equilibrio. ${ }^{17}$ No reduce a sus competidores, los extermina; no proyecta la durabilidad de su enriquecimiento, absorbe hasta agotar la fuente. Con todo, esta depredación posee significados críticos que subyacen al proceso de explotación desplegado. A decir de Paula Vásquez (2019, 160-161), se trata de un "proyecto depredador sin control", que se entreteje con "el debilitamiento de las instituciones del Estado venezolano, que, sin una visión a largo plazo, solo apunta a consolidar mecanismos que sirvan para enriquecer a una minoría corrupta". ${ }^{18}$

Como resultado de esta práctica, cada fuente de riqueza cartelizada parece condenada a su destrucción. Con el Estado operando como holding de carteles, sus funciones no poseen otro destino que proceder de la misma manera. Si todas las fuentes de riqueza del país se encuentran disponibles desde el Estado, la destrucción de cada una de ellas parece un hecho insoslayable, como sucedió con la energía eléctrica. La cartelización del circuito energético, es decir, el control directo y excluyente del proceso de generación, transmisión, distribución y comercialización de la electricidad, condujo a su extinción. Como lo veremos, de la prestación de un servicio se pasó a la cartelización de su ciclo económico,

\footnotetext{
${ }^{17}$ En otras especies, la depredación no persigue el exterminio; opera dentro de leyes naturales que garantizan equilibrios sistémicos.

18 "Este proyecto depredador incontrolado, basado en una estructura de poder muy poco democrática, también puede explicarse por otros factores: la disminución de la producción de petróleo convencional, especialmente los aceites de la cuenca del lago de Maracaibo, los cambios energéticos globales, la presencia activa de China y sus necesidades energéticas. Estos factores se combinan con el debilitamiento de las instituciones del Estado venezolano, que, sin una visión a largo plazo, solo apunta a consolidar mecanismos que sirvan para enriquecer a una minoría corrupta" (Vásquez 2019, 160-161).
} 
destruyendo su infraestructura y agotando el propio funcionamiento del circuito como fuente de riqueza.

Conviene subrayar que tras esa lógica depredadora y sin equilibrio se encuentra el funcionamiento de un mercado que, característico de los carteles, es ilegal, pero en el caso sui generis del Estado venezolano, ha sido superpuesto con mercados legales en un entramado de negocios centralizado que funciona como los monopolios, en beneficio exclusivo de las redes antes mencionadas. En el caso de los carteles, precisamente, a los aspectos clásicos de un mercado formal (producción, distribución, comercialización), se suman otros que son propios de los mercados ilegales, como el lavado de dinero. ${ }^{19}$ De allí que la tercerización resulta fundamental en el despliegue de la cartelización, y en la trama construida sobre el circuito energético venezolano ha quedado muy claro el asunto.

Pensamos que una descripción del problema contribuye con la necesidad de "conocer cómo opera ese mercado y cuáles son sus agentes" (Carrión y Pinto 2017, 82), pues en el entramado subyacente al negocio hallamos las relaciones de poder establecidas desde 1999; o bien, a través de su conocimiento específico comprendemos el sentido real de esas relaciones. "En la actualidad, los mercados ilegales, dada su penetración mundial y las cualidades de la llamada nueva economía, siguen a la dinámica de las grandes corporaciones mundiales; esto es, una organización de la actividad económica espacialmente dispersa pero globalmente integrada" (Carrión y Pinto 2017, 83).

El colapso de la energía eléctrica en Venezuela, con efectos devastadores sobre la población, es un ejemplo del proceso de cartelización mencionado, cuyo final evidenció la destrucción de un servicio tratado con criterio de depredación. ${ }^{20}$ No se trata de un ejemplo al azar, sino

19 "Las economías ilegales como la industria de la cocaína, lo mismo que la economía legal, están determinadas por la producción y el intercambio, en el mercado, de bienes y servicios, y orientadas en función de los costos, precios y expectativas de ganancia" (Dombois 1998, 3).

${ }^{20}$ El 7 de marzo de 2019, cerca de las 17.00 hrs. tuvo lugar el colapso energético que produjo un apagón nacional que, según las regiones, alcanzó hasta 110 horas continuas de interrupción del servicio. En estados de menor afectación, el apagón impactó entre el 7 y el 9 de marzo, con interrupciones de 12 a 16 horas continuas, e intervalos breves de restauración del servicio. Un segundo apagón de la misma magnitud ocurrió entre el 25 y el 28 de ese mes. Los únicos medios de comunicación que funcionaron durante la crisis se redujeron a las redes sociales. Según la Sociedad Venezolana de Nefrología y la Red Nacional de Médicos por la Salud, en sus publicaciones por Twitter, indicaron hasta 
del caso que, gracias a la forma de explotación puesta en práctica por el recurso de la cartelización, acabó en catástrofe. El proyecto de poder instaurado en 1999 transformó el circuito energético en una fuente de riqueza cartelizada, aplicando sobre su ciclo económico formal una lógica de empresa ilegal interconectada con circuitos globales de capitales asociados con el Estado, operados en el país por redes de corrupción y criminalidad entramadas sobre plataformas institucionales.

\section{TRAMA PARA UNA ENERGÍA VULNERADA}

El 2 de mayo de 2007, Hugo Chávez, en su condición de Presidente de la República, firmaba el Decreto $\mathrm{N}^{\circ} 5.330$ que sancionaba la Ley Orgánica de Reorganización del Sector Eléctrico, “dada la importancia que tiene el servicio eléctrico para el desarrollo del país y el bienestar social". ${ }^{21}$ Se fundaba así la Corporación Eléctrica Nacional, Corpoelec, organismo que a partir de entonces - según indica la ley que la creó-, se encargaría de "la realización de las actividades de generación, transmisión, distribución y comercialización de potencia y energía eléctrica". Desde ese momento, todo lo concerniente al circuito energético quedaría centralizado en esta "empresa operadora estatal", sumiendo en ella las actividades de unas 19 empresas públicas y privadas que hasta ese año venían prestando los servicios indicados (desde la generación hasta la comercialización). Corpoelec fusionaba, de esa manera, a todas las empresas públicas y privadas bajo sus operaciones; se había estatizado la energía eléctrica de Venezuela.

El decreto y su significado, en el seno de un proyecto socialista, no habría de llamar la atención, y apenas podría entenderse como un movimiento característico en una política por el estilo, si no hubiese tenido

54 pacientes fallecidos por deficiencias en las atenciones hospitalarias. En varias ciudades hubo saqueos y disturbios, mientras que los asesinatos, así como las ejecuciones extrajudiciales, aumentaron sus cifras durante esos días.

${ }^{21}$ Publicado en Gaceta Oficial, $N^{\circ} 38.736,31$ de julio de 2007: 355.883-355.884. Existía, desde 2001, la Ley Orgánica del Servicio Eléctrico, la cual regía "las actividades de generación, transmisión y gestión del Sistema Eléctrico Nacional, así como la distribución y comercialización de potencia y energía eléctrica. Establece que la generación y comercialización están abiertas a la competencia, las actividades de transmisión y distribución están sujetas a concesión" (Urdaneta et al. 2009, 47). La modificación de 2007 garantizó al Estado la exclusión de la competencia en el asunto. 
lugar en el país que posee una de las centrales hidroeléctricas más grandes del mundo, la cual ocupó el primer lugar en su tipo hasta $2013 .^{22} \mathrm{La}$ eficiencia del sistema, especialmente la capacidad generadora instalada, ha permitido a su vez la exportación de energía, vendida a Brasil desde 2001 a través de una línea que llega a Boa Vista e ilumina parte del estado Roraima.

Sin embargo, es importante comprender la diferencia entre capacidad instalada y capacidad disponible, pues a pesar de la aparente suficiencia del sistema, ya entre 2008 y 2009 inicia un déficit en la cobertura de la demanda que no será resuelto en adelante (Saturno y Sánchez 2019 , 28). La generación "total teórica" de energía ya no se correspondía con su capacidad real en ese momento, hallándose por debajo, inclusive, de la reserva del $30 \%$ que debe existir por encima de la demanda que "las buenas prácticas" aconsejan (Villegas et al. 2010, 3). ${ }^{23}$ Ya por entonces, el análisis de la situación conducía a afirmar que "la disponibilidad real de generación de potencia eléctrica es deficitaria con respecto a la demanda máxima del sistema" (Villegas et al. 2010,3).

Hacia 2007 existía una indisponibilidad del 30\% en las plantas térmicas y del $10 \%$ en las centrales hidráulicas. Además, "el 79\% del parque de generación tiene más de 20 años de antigüedad" (Villegas et al. 2010, 3), lo que contribuye a que el SEN sea susceptible ante variables climáticas que intervengan sobre la capacidad generadora del Guri, responsable de producir el $60,4 \%$ de la energía consumida en Venezuela (Peña et al. 2013, 779). Si en 2008 el SEN pudo responder a la demanda, aunque de manera deficitaria, fue por contar con altos volúmenes de agua en el embalse, gracias a un año generoso en pluviosidad. Poco después se comprobaría la susceptibilidad señalada.

\footnotetext{
${ }^{22}$ La Central Hidroeléctrica Simón Bolívar, ubicada en el embalse del Guri, es actualmente la tercera más grande del mundo, y su embalse es el séptimo en capacidad. En el año 2010, además, Venezuela alcanzaba un $98,42 \%$ de cobertura nacional del servicio eléctrico. Su capacidad generadora en 2008 era de 23.154 MW, producida por energía hidráulica (63\%) y térmica ( $37 \%$, de combustible fósil), lo que indica, asimismo, que el país contó con una importante redundancia en la generación suficiente como para cubrir su demanda, ubicada ese mismo año sobre los 16.351 MW. Datos tomados de: Centro Nacional de Gestión del Sistema Eléctrico (2008). Ver también Saturno y Sánchez (2019).

${ }^{23}$ Estudios indican que la energía generada en 2009 fue de 123.390 gigavatios/hora, mientras que el consumo fue de 123.017 gigavatios/hora (Urdaneta et al. 2009, 47; también ver Peña et al. 2013, 778).
} 
Ciertamente, el 2009 fue un año extremadamente seco, efecto del fenómeno El Niño. Los niveles del embalse alcanzaron mínimos históricos, impactando severamente en la capacidad generadora. El ciclo hidrológico de 2009 produjo caudales $13 \%$ inferiores a la media del río Caroní, que asiste al embalse: "Una reserva nominal de energía inferior al $10 \%$, con una indisponibilidad importante de las plantas térmicas, dificulta enfrentar ciclos hidrológicos secos sin recurrir al racionamiento programado" (Villegas et al. 2010, 4). Este año, es decir, dos años después del decreto que estatizaba las empresas de energía eléctrica, Chávez creaba el Ministerio del Poder Popular para la Energía Eléctrica (MPPEE), profundizando aún más la centralización excluyente del circuito energético.

En el propio 2009, debido a la dependencia del caudal del río Caroní y a causa de sus bajos niveles, el SEN produjo 339 interrupciones del servicio mayores a $100 \mathrm{MW}$, incrementando en más del 100\% el número de cortes del año anterior y llegando a una cifra jamás alcanzada. ${ }^{24}$ En enero de 2010, el presidente Chávez decretó la reducción del horario de trabajo en la administración pública con el objeto de ahorrar energía; en febrero decretaba la emergencia nacional al respecto, permitiendo así a Corpoelec y al MPPEE adquirir equipos de generación mediante contratación directa. ${ }^{25} \mathrm{La}$ emergencia debía durar sesenta días, pero luego fue prorrogada hasta en dos oportunidades ese mismo año.

Después de esta emergencia, y en correspondencia con la estatización absoluta del servicio, entre 2010 y 2015 se invirtieron unos 40 mil millones de dólares para resolver las dificultades (Saturno y Sánchez 2019, 23). "El problema actual no es consecuencia de una falta de inversión, el gobierno nacional asignó importantes sumas de dinero al sector eléctrico; el problema ha sido la centralización, burocratización y pésima asesoría extranjera en el direccionamiento de esas inversiones"

${ }^{24}$ Cada falla de 100 MW equivale a dejar sin servicio a unas 250 mil personas (Peña et al. 2013, 780; también, Saturno y Sánchez 2019, 32).

${ }^{25}$ Sobre el cambio de horario: Decreto $\mathrm{N}^{\circ} 7.175$ del 13 de enero de 2010, Gaceta Oficial, $\mathrm{N}^{\circ} 39.345$. El horario laboral de la administración pública se reducía al intervalo de 8.00 am a $1.00 \mathrm{pm}$. Ya se habían decretado meses atrás ciertas medidas de ahorro de electricidad en las dependencias gubernamentales: Decreto $\mathrm{N}^{\circ} 6.992$ del 21 de octubre de 2009, Gaceta Oficial, No 39.298, 3 de noviembre de 2009. El decreto de emergencia: Gaceta Oficial, $\mathrm{N}^{\circ} 39.363,8$ de febrero de 2010, Decreto $\mathrm{N}^{\circ} 7.728$ sobre Estado de emergencia del servicio eléctrico. 
(López-González 2018). ${ }^{26}$ La estatización condujo, a su vez, a la imposibilidad de la participación de empresas privadas en el circuito energético. El Estado, operando así como un cartel, se había garantizado el acceso exclusivo al capital vinculado con la energía eléctrica.

Si la estatización comenzó en 2007 con Corpoelec, el año anterior había comenzado la Misión Revolución Energética, impulsada por el propio Chávez, cuyo nombre tomaba de un programa similar llevado a cabo por Cuba desde el año 2000. ${ }^{27}$ En 2006 arrancó un 'plan piloto' que supuso la instalación gratuita de 52 millones de bombillos ahorradores ${ }^{28}$ con los que se pretendía reducir el consumo de energía en 2.000 MW (PDVSA 2006). En enero de 2010 ya se habían instalado más de 79 millones a nivel nacional; hacia 2015 la cifra alcanzó los 180 millones de bombillos ahorradores (Asamblea Nacional 2017, 112). El impulso hacia la sustitución de bombillos incandescentes por ahorradores parece haber sido el antecedente más conspicuo de las inversiones millonarias que el Estado puso en marcha para la administración de la energía eléctrica en su provecho. Asimismo, y en medio de la crisis energética que la sequía impuso en 2009, se daba otro paso firme hacia una escalada de inversiones que tiempo después demostraba su ineficiencia. En transparente proximidad con el gobierno fue creada Derwick Associates, empresa venezolana de ingeniería dedicada a la fabricación de plantas generadoras. Entre 2009 y 2010, esta empresa ejecutó 11 contratos con el Estado, instalando plantas termoeléctricas. De estos "grupos electrógenos", con capacidad de 1.100 MW cada uno, "ni el 10\%" estaban operativos en 2019 al momento del colapso. El costo de estos aparatos fue de 200 millones de dólares cada uno (López-González 2019). ${ }^{29}$

\footnotetext{
${ }^{26}$ El Informe Final de la Comisión Mixta para el estudio de la crisis eléctrica en el país de la Asamblea Nacional $(2017,5)$, indica que fueron 42 mil millones de dólares.

${ }^{27}$ El nombre de la misión es idéntico al que utilizó Cuba en el año 2000 (Asamblea Nacional 2017, 112); en 2004 se suscribiría un acuerdo de cooperación energética con La Habana, y en 2006, como se indica, inicia el programa con el mismo nombre en Venezuela.

${ }^{28}$ Bombillo, bombilla o ampolleta, según diferentes denominaciones usadas en el español para designar el mismo término.

${ }^{29}$ Además, López-González (2019), quien trabajó "por más de 12 años en PDVSA y el Ministerio de Energía Eléctrica", afirma lo siguiente: "A partir de la centralización del sistema eléctrico (...) todas las máquinas a comprarse para el parque termoeléctrico serían Siemens. (...) Cabe recordar que la empresa Siemens tiene demandas a nivel internacional por corrupción y competencia desleal, basadas en sobornos a funcionarios de gobiernos
} 
Gracias a un convenio de acuerdos-marco de cooperación energética suscrito con La Habana en 2004, el Estado inició en 2010 la instalación de "motores de generación distribuida" con la intermediación de Cuba para la adquisición e instalación de las máquinas. El objetivo con esta estrategia era aportar al SEN unos 1.000 MW, asistiendo especialmente a poblados y regiones alejados del sistema interconectado. La operación alcanzó a adquirir y poner en funcionamiento hasta 969 motores de generación distribuida entre 2010 y 2015 (Asamblea Nacional 2017, 114). ${ }^{30}$

Junto a otras empresas, Derwick Associates sirvió de velo a la cartelización del circuito energético venezolano. En apariencia, el Estado estaba contratando con una empresa privada, lo que parecía indicar que no existía tal estatización; no obstante, todas las contrataciones se dieron directamente con Corpoelec y Petróleos de Venezuela S.A. (PDVSA), y en el caso de la adquisición de las plantas y recursos tecnológicos, la intermediación de Cuba, amparada en los convenios suscritos, hizo las veces de plataforma donde tenían lugar las transacciones. La estatización del circuito energético, que garantizó a Corpoelec la libertad de contrataciones directas y la ventaja exclusiva para la adquisición de equipos y maquinarias, aseguró una circulación cerrada de capital entre el Estado y las empresas beneficiadas, todo bajo la tercerización estratégica de La Habana:

La procura de los equipos no fue realizada directamente entre PDVSA y los fabricantes MTU (Alemania), Guascor (España), Scania (Suecia), SDM (Francia), Volvo (Suecia) y Cymasa (España).

de países en vías de desarrollo para imponer sus modelos de turbinas ante las turbinas General Electric, claramente mucho más fiables y de mejor calidad, en términos generales. Empresas alemanas como Volkswagen se han visto recientemente involucradas en fraudes como los ocurridos en Estados Unidos con sus modelos a gasoil, donde evadieron los controles de la Agencia Ambiental (EPA) para falsear los datos de las emisiones de combustible de sus vehículos".

${ }^{30}$ Cuando se inauguró una de estas plantas en la isla de Margarita, el entonces director gerente de Corpoelec, Maximiliano Soto, declaró: "Gracias al convenio Cuba-Venezuela, nosotros contamos actualmente con más de 40 plantas que aportan al Sistema Eléctrico Nacional 596 MW de los 1.000 MW que están proyectados en esta misión; y al recibir el apoyo del Ejecutivo Nacional, antes de la fecha propuesta estaremos entregando al pueblo venezolano 83 plantas que garantizarán luz en los lugares más recónditos del territorio nacional" (Sistema Bolivariano de Información y Comunicación 2010). El papel de los técnicos cubanos en este proceso era el de 'adiestrar' a los beneficiados en el mantenimiento de las plantas instaladas. Según la Asamblea Nacional (2017, 112), "las asesorías y programas de formación costaron 4.797 millones de dólares". 
Fueron comprados a través del convenio Cuba-Venezuela, fungiendo como intermediario principal la Unión Eléctrica de Cuba. ${ }^{31}$

Los motores de generación distribuida, todos, provinieron de $\mathrm{Cu}$ ba. ${ }^{32}$ Es así como la estatización operó como un cartel, excluyendo del negocio a otros competidores y cerrando el acceso a las transacciones con la tercerización de otro país y una serie de recursos jurídicos provenientes del Estado que blindaron las operaciones. Aquel decreto de emergencia eléctrica con el que Chávez impulsaba el asunto fue repotenciado en 2013 cuando Nicolás Maduro lo reactivó, esta vez acompañado de la militarización de las instalaciones. La defensa militar del circuito energético, incluyendo a las plantas generadoras, corría una cortina oscura sobre el negocio. ${ }^{33}$

Quizás el ejemplo más dramático provenga de la región menos asistida, que corresponde a los estados Zulia y Falcón, al occidente del país, el extremo más lejano del sistema interconectado proveniente del Guri. Para subsanar el problema de la distancia, en 2001 se instaló "el primer ciclo combinado del país" (Termozulia I), con funcionamiento a gas natural. El proyecto, original de la extinta empresa Enelven (Energía Eléctrica de Venezuela), que asistía a la región, debía alcanzar hasta

\footnotetext{
${ }^{31}$ Ver también Saturno y Sánchez $(2019,88)$. Sobre las empresas, dice el Informe Final de la Asamblea Nacional $(2017,15)$ : "Los representantes de las empresas Consorcio OIV, Elecnor, Ferrostaal, Duro Felguera, Derwick Associates, Energing, Alstom, China CAMC, Indigo, comparecieron de forma oportuna ante la comisión mixta suministrando información parcial acerca de sus proyectos. Ninguna empresa entregó copia de los contratos suscritos con el Estado venezolano a través de Corpoelec, sus filiales, PDVSA y CVG. Las restantes empresas no atendieron la invitación realizada por la comisión mixta. En particular, las empresas Energy Parts Solutions, GTME, Solar Turbines, UNE Cuba, Gamesa, Pro Energy, Ovarb y Tradequip no pudieron ser localizadas en Venezuela".

${ }^{32}$ El monto total del gasto vinculado a los bombillos y la generación distribuida fue de 6.323 millones de dólares, según estimaciones indicadas en el Informe Final (Asamblea Nacional 2017, 114).

33 "Venezuela declara en emergencia su sistema eléctrico para estabilizarlo" (Corpoelec 2013). Jorge Arreaza, entonces vicepresidente de la República, agregaba: "Se ordena a los organismos de seguridad ciudadana y a la Fuerza Armada, el resguardo inmediato del sistema eléctrico con el objetivo de impedir actos vandálicos o atentados y cualquier tipo de sabotaje" (Corpoelec 2013). El decreto: Gaceta Oficial, $N^{\circ} 40.151$, Decreto $N^{\circ} 09$, Estado de excepción del sistema eléctrico nacional, 22 de abril de 2013. Como ejemplo de este blindaje producido desde los acuerdos suscritos con Cuba en 2004, en el período que va entre 2005 y 2015 se aprobaron 42 proyectos contratados por el Estado: solo 4 de ellos se hicieron bajo licitación pública (Asamblea Nacional 2017, 11).
} 
cuatro generadores más (Termozulia II a V); sin embargo, hacia 2018, "aunque se han comprado los equipos, se han iniciado las obras, no se ha completado ninguno de estos ciclos combinados y el dinero fue ciertamente asignado por el gobierno nacional" (López-González 2018).

En el occidente de Venezuela existen reservas de gas natural que superan las que posee Colombia, por ejemplo; contando con este combustible, PDVSA debió invertir en la extracción del gas para alimentar las plantas Termozulia II a V, pero esto nunca sucedió. Las máquinas diseñadas para funcionar con gas acabaron funcionando con gasoil: "De esta manera, la república derrocha 6 millones de litros al día para generar electricidad en plantas diseñadas para funcionar con gas natural, a las que se fuerza a funcionar con gasoil provocando un incremento del $300 \%$ en la tasa de fallas y un incremento en los costes de mantenimiento" (López-González 2018). ${ }^{34}$

A pesar de todo ello, Venezuela ocupó el primer lugar de consumo de energía eléctrica per cápita en América Latina en 2016 (Corpoelec 2013). No obstante, los problemas estructurales que se sembraron desde la estatización en 2007 colocarían al servicio eléctrico del país en un camino sin regreso hacia su deterioro definitivo. Una investigación sobre los 'riesgos operacionales' en el SEN identificó una serie de 'fuentes' al respecto: el sobredimensionamiento de la central hidroeléctrica del Guri, generadora de más del $60 \%$ de la energía que consume el país; la irregularidad en el caudal del rio Caroní, altamente susceptible a las variaciones climáticas; deficiencias en los planes de inversión, por desvío de recursos, corrupción, o la desatención sistemática a los problemas, con el ejemplo dramático del occidente venezolano y las plantas de ciclo combinado; la imposibilidad de restablecer el Sistema Interconectado Nacional, al depender casi exclusivamente de la central del

\footnotetext{
${ }^{34}$ Continúa López-González: "El gasoil es un combustible que ya no se usa para generación de electricidad debido a que provoca emisiones acidificantes de la atmósfera que provocan la llamada lluvia ácida, deteriorando los suelos y las cosechas agrícolas. De hecho, el único país que apuesta hoy fuertemente a la electrificación con gasoil, en Latinoamérica, es la República de Cuba". Otro aspecto que da cuenta de las contradicciones entre inversión y planificación se observa con el desarrollo de las centrales hidroeléctricas en el país. Por ejemplo, Macagua II y Macagua III, también sobre el río Caroní, se iniciaron en 1995 con el objetivo cumplido de que entraran en funcionamiento en 1997. Caruachi, igualmente en el Caroní, tuvo un atraso de seis años y entró en funcionamiento en 2006; Tocoma, en el mismo río, aún no se termina y ya cuenta con 15 años de retraso.
} 
Guri, pues cualquier perturbación en el lugar impide el restablecimiento inmediato del servicio; el retraso en los planes de inversión y mejora de las líneas de transmisión, que va de la mano de las deficiencias en las inversiones; y la disminución de la productividad de los recursos humanos, factor clave en el mantenimiento y en la atención temprana de las interrupciones del servicio (Peña et al. 2013, 778-780). ${ }^{35}$ Todo esto, como se observa, ya era un problema hacia el año 2010, por lo que el aumento de tales condiciones fue un tobogán sin obstáculos hacia el colapso.

La crisis energética fue, por tanto, acumulativa y progresiva. Cuando una nueva sequía asoló al país en 2015, el entonces ministro del MPPEE Jesse Chacón, hombre cercano a Chávez y clave en la trama del circuito energético, advirtió a Maduro sobre "la necesidad de tomar medidas para la recuperación de la generación térmica requerida para afrontar la disminución previsible de la generación hidroeléctrica" (Asamblea Nacional 2017, 5). ${ }^{36}$ Todos lo sabían; la energía ya no daba para más.

En 2018 se estimó que solo el 37,7\% de la capacidad generadora de energía eléctrica estaba en funcionamiento. En el déficit tenía un enorme peso el sistema termoeléctrico, el negocio del siglo XXI en la Venezuela socialista, indispuesto en un 78\%. En 2017 se contabilizaron hasta 18.221 apagones; solo en el Zulia hubo 2.478. El 22 de febrero de 2018, en presagio de lo que sucedería un año después, tuvo lugar un apagón con una pérdida de $9.000 \mathrm{MW}$ de servicio, afectando severamente al occidente del país. Ante la situación, ya con el sistema energético en caída libre, se tomaron medidas que nunca fueron suficientes para resolver las emergencias; todo lo contrario, daban cuenta de la falta de racionalidad en las soluciones, o bien del desinterés en el "bienestar social" que Chávez anunció cuando estatizaba el SEN en 2007: "Lo que se ha dicho es que Corpoelec raciona diariamente entre $2.000 \mathrm{MW}$ y $2.500 \mathrm{MW}$ a nivel nacional. Tal racionamiento es rotativo, y es por un

\footnotetext{
35 El Informe Final de la Asamblea Nacional (2017) coincide con este diagnóstico, además de aportar una inmensa cantidad de información sobre el problema central: la corrupción.

${ }^{36}$ La advertencia de Chacón fue presentada a Maduro en el punto de cuenta 017-2015 del 16 de mayo de 2015. Evidentemente, no se tomaron las medidas necesarias. La Comisión Mixta concluyó al respecto que "La operación del sistema se ha realizado utilizando criterios políticos y no técnicos" (Asamblea Nacional 2017, 45).
} 
máximo de 2 a 3 horas, en el área o población que le toque" (Hernández 2018, 30). El colapso total llegó en marzo de 2019.

Conviene subrayar que parte de la indisponibilidad del parque termoeléctrico procede de la falta de combustible, cuyo origen se asienta en la explotación de otro recurso con la misma lógica: el petróleo. A pesar de haber recurrido al desarrollo del complemento energético de la mano del combustible fósil, lo cual parece coherente en un país petrolero con las mayores reservas del planeta, esto nunca fue atendido con criterios de sostenibilidad. Ni siquiera la considerable caída en la demanda anual de energía que el país ha experimentado desde hace unos años, ha podido ser satisfecha con las condiciones en las que se encuentra el SEN. A la falta de mantenimiento y renovación del sistema, ya denunciado en tiempos de Chávez, se sumaron ciclos hidrológicos negativos, lo que se ha visto agravado con la carencia de combustible. El petróleo, tratado con el mismo criterio depredador que la electricidad, hoy no es capaz de abastecer el combustible necesario para que el parque termoeléctrico funcione. Progresiva y sistémica, la crisis de la energía es el resultado indefectible de una explotación abrasiva y voraz. Es la depredación sin criterio de equilibrio. ${ }^{37}$

\begin{tabular}{lrccccc}
\hline${ }^{37}$ Capacidad instalada y disponible frente a demanda máxima, $1983-2017$ \\
\hline SEN & 1983 & 1998 & 2009 & 2013 & 2015 & 2017 \\
Capacidad instalada (MW) & 9.955 & 19.696 & 23.708 & 30.291 & 31.761 & 36.560 \\
Capacidad disponible (MW) & S/D & 14.200 & 16.495 & 17.456 & 17.720 & 13.800 \\
Demanda máxima (MW) & 4.655 & 10.854 & 17.337 & 18.696 & 18.129 & 14.007
\end{tabular}

Caída de la demanda anual en Venezuela, 2013-2017

\begin{tabular}{lccccc}
\hline & 2013 & 2014 & 2015 & 2016 & 2017 \\
Demanda máxima (MW) & 18.696 & 18.481 & 18.129 & 16.967 & 14.007 \\
\hline
\end{tabular}

Fuente: elaboración propia sobre la base de información recabada para este trabajo.

Con una migración estimada en más de 4 millones hacia junio de 2019, la caída del consumo per cápita superaría el $10 \%$, si tomamos en cuenta que la población venezolana ronda los 30 millones de habitantes. Por otro lado, las medidas tomadas para reducir el consumo energético a gran escala obligaron al cierre/quiebre de muchas empresas e industrias en el país, lo que también contribuye con la reducción del consumo. "La demanda eléctrica proyectada en planes de hace 20 años para el 2018 fue de 28.900 MW. Hoy dicha demanda se sitúa en 14.000 MW. Es decir, una disminución de 14.900 MW, y cuya distribución es la siguiente: diáspora venezolana (1.750 MW); desaceleración economía industrial (2.250 MW); desaceleración economía comercial y servicios (1.750 $\mathrm{MW}$ ); incumplimiento plan petrolero (2.950 MW); incumplimiento plan Guayana (2.800 $\mathrm{MW})$; racionamiento Guayana (2.400 MW) y otras restricciones (1.000 MW)" (Hernández 2018, 28). 
Tabla 1: SÍNTESIS DEL PROCESO DE DESTRUCCIÓN DEL SISTEMA ELÉCTRICO NACIONAL DE VENEZUELA

\begin{tabular}{lll}
\hline Fecha & \multicolumn{1}{c}{ Hechos } & \multicolumn{1}{c}{ Situación del SEN } \\
\hline 2000 & $\begin{array}{l}\text { Inicia Misión Revolución Energética de } \\
\text { Cuba. }\end{array}$ & \\
2001 & Ley Orgánica del Servicio Eléctrico. & $\begin{array}{l}\text { Se instala Termozulia I. } \\
\text { Se inaugura la línea Guri-Boa Vis- } \\
\end{array}$ \\
& ta.
\end{tabular}

2004 Convenio de acuerdos-marco de cooperación energética suscritos con Cuba.

2006 Inicia Misión Revolución Energética de Arranca 'plan piloto' con la instaVenezuela. lación de 52 millones de bombillos ahorradores.

Entra en funcionamiento Caruachi.

2007 Ley Orgánica de Reorganización del Indisponibilidad del 30\% en las Sector Eléctrico. Se crea Corpoelec. plantas térmicas y del $10 \%$ en las centrales hidráulicas.

2009 Se crea el Ministerio del Poder Popular Sequía produce caudales 13\% infepara la Energia Eléctrica, MPPEE. riores a la media del rio Caroní. Se funda Derwick Associates. 339 interrupciones del servicio Entre 2009 y 2010, Derwick Associa- eléctrico mayores a 100 MW. tes ejecuta 11 contratos con el Estado, instalando plantas termoeléctricas por US\$200 millones cada una.

2010 Enero: Chávez decreta el cambio de 98,42\% de cobertura nacional del horario en la administración pública SEN.

para ahorrar energía.

Instalados 79.829 .924 bombillos Febrero: Decretada emergencia nacio- ahorradores.

nal. Se autoriza a Corpoelec a la con- Comienza la instalación de los motratación directa. tores de generación distribuida.

Se contratan asesores cubanos para el Este año se alcanzan a instalar 83 adiestramiento de vecinos en la insta- plantas.

lación, mantenimiento y cuidado preventivo de los motores de generación distribuida.

2013 Maduro decreta emergencia eléctrica y militariza las instalaciones del SEN.

2015 Entre 2005 y 2015 se aprobaron 42 Instalados hasta esa fecha 180 proyectos contratados por el Estado: millones de bombillos ahorradores solo 4 de ellos se hicieron bajo licitación y 969 motores de generación dispública. tribuida.

Se consumieron más de U\$40.000 millones con la estatización del SEN. 
2016 Venezuela ocupa el primer lugar de consumo de energía eléctrica per cápita en América Latina.

2017 Se estima que lo gastado en bombi- Se contabilizaron hasta 18.221 llos y generación distribuida fue de apagones; solo en el Zulia hubo US\$6.323 millones. 2.478 .

Las asesorias de los cubanos vinculadas a los motores de generación distribuida costaron US\$4.797 millones.

2018 Corpoelec raciona diariamente entre 2.000 MW y 2.500 MW a nivel nacional. El racionamiento es rotativo, por un máximo de 2 a 3 horas en regiones y lugares afectados sin mayor sistematicidad.

Solo funciona el $37,7 \%$ de la capacidad generadora de energía eléctrica.

El sistema termoeléctrico se halla indispuesto en un $78 \%$.

El funcionamiento de las plantas instaladas por Derwick Associates no llega ni al $10 \%$.

22 de febrero de 2018: apagón afecta al occidente del pais por varios dias.

20197 de marzo: apagón que deja sin energía eléctrica al pais y se prolonga por más de cien horas en algunos estados del occidente. En ese mes tuvieron lugar varias interrupciones del servicio con alcance nacional, y otras más ocurririan en meses siguientes.

Colapso total del SEN. Desde entonces, el servicio no ha sido continuo ni estable en ninguna parte de Venezuela.

Fuente: elaboración propia sobre la base de información recabada para este trabajo.

\section{LA DESTRUCCIÓN INSOSLAYABLE}

El estudio de los carteles, tanto en lo criminológico como en lo sociológico, ha estado enfocado generalmente en 'empresas ilegales' que operan bajo la "amenaza de la sanción estatal". ${ }^{38}$ Lo que observamos aquí es una economía cartelizada desde el Estado el cual, al ser utilizado como plataforma para el efecto, neutraliza su función fiscal y sancionatoria. No se trata de grupos ilegales, sino de redes entramadas en instituciones públicas, en organizaciones políticas y en corporaciones financieras internacionales que actúan bajo marcos jurídicos legítimos,

${ }^{38}$ Sobre los enfoques en el estudio de los carteles, ver Dombois $(1998,3)$; sobre la forma de operar, ver Krauthausen $(1994,115)$. 
encubriendo así sus actividades corruptas y delictivas. ${ }^{39}$ La práctica cartelizada se encuentra en la forma de realizar los negocios, desde su origen captador de riquezas hasta su transformación en capital. Son transacciones que tienen lugar en la intersección del mundo legal y del ilegal, bajo la protección del Estado en sí mismo, que actúa como un holding.

La práctica venezolana da cuenta de su condición original, o bien, sui generis. El recurso de la cartelización, como indicamos, es el efecto de decisiones que entrelazan objetivos políticos y económicos, veladas tras el despliegue ideológico de la revolución, cuyo horizonte ha sido, desde su concepción, la satisfacción de intereses en beneficio de clases que no habían participado en el reparto de riqueza durante el modelo liberal bipartidista. De allí que la destrucción del modelo derrotado en las elecciones de 1998 haya sido el camino ineludible para lograr tales

\footnotetext{
${ }^{39} \mathrm{El}$ caso del poder judicial en Venezuela es un indicador fehaciente del control político directo sobre las decisiones que benefician las operaciones de las redes entramadas en el Estado para su enriquecimiento y actividades libres de sanciones o fiscalizaciones. A su llegada al poder, Chávez prometió una 'reestructuración' del poder judicial y al efecto lo declaró en emergencia. Para protegerse de debates y trabas en sus objetivos, el mandatario logró que se reformara el mecanismo de decisiones en la Asamblea Nacional (AN), logrando que todos los debates se decidiesen por mayoría simple, algo que le garantizó al socialismo bolivariano una escalada de reformas en su favor por contar, como en efecto lo hizo desde 1999 hasta 2015, con la mayoría de los diputados a su favor en la asamblea. La reforma definitiva de la Ley Orgánica del Tribunal Supremo de Justicia (TSJ) tuvo lugar en 2004 con la aprobación del proyecto en la AN por mayoría simple, precisamente. En adelante, todos los magistrados elegidos desde la AN contaron con un perfil abiertamente partidario por las ideas y propuestas oficialistas, con manifiestos, declaraciones, sentencias, decisiones y hasta expresiones públicas, en apoyo y compromiso con el socialismo, tal como si la ideología al respecto fuese el espíritu detrás de leyes y proyectos. "Al revisar la actuación de la Sala Constitucional del TSJ desde la designación de los nuevos magistrados en 2004 hasta 2013, se observa que no ejerció ningún tipo de control de constitucionalidad sobre los poderes públicos nacionales, en especial sobre el Presidente de la República, cuyos actos no fueron nunca cuestionados a través de amparo constitucional, acciones de anulación o cualquier otra vía procesal" (Cánova et al. 2014, 421). El secuestro de los poderes públicos en beneficio de las operaciones de los carteles que ocupan el Estado fue absoluto hasta 2015, cuando por primera vez la oposición ganó por vía electoral la mayoría parlamentaria, lo que le permitió disputar el poder al socialismo bolivariano. Esto condujo, en correspondencia con lo observado, a que el Estado, apoyado en el TSJ, inhabilitara a la AN y anulara su poder de decisión, en una franca demostración de autoritarismo que prolonga el secuestro de los poderes públicos, espacio que, en manos de la oposición, ponía en riesgo la libertad de sus operaciones y negocios.
} 
objetivos. En ese movimiento no solo se destruía un modelo de poder: también se apuntaba a la defenestración de todo cuanto le representaba. Uno de sus símbolos más conspicuos, desde luego, lo encarna la clase media.

En Venezuela, quizás hasta mediados del siglo XX, no existía la clase media; por lo tanto, es un producto histórico y social que surgió con el proceso de transformación económica e industrial del país a mediados del siglo pasado, y acabó por consolidarse con el modelo liberal. La revolución liderada por Chávez y su discurso apuntó hacia ella como el símbolo a destruir, 'la burguesía', el enemigo ideológico, pero también el competidor en todos los planos. La clase media era la franja de la sociedad llamada a crecer materialmente, la depositaria de la ética liberal, cuya estética personificaba la exclusión social en sí misma, la marca de la diferencia material y subjetiva. Chávez capitalizó muy bien el malestar político existente con la crisis del bipartidismo y lo convirtió en malestar social, en resentimiento políticamente activo, en efectuación ideológica de su proyecto. ${ }^{40}$

\footnotetext{
${ }^{40}$ El fin de la dictadura de Juan Vicente Gómez (1908-1936) supuso la apertura hacia la transformación industrial de la explotación petrolera. Esto coincide, asimismo, con la progresiva profesionalización de las empresas extractivas que aprovechaban el recurso en el país, que tendrá un impulso significativo con la Segunda Guerra Mundial, cuando Venezuela se convierta en abastecedor estratégico de Estados Unidos, así como tendrá un desarrollo decisivo al final de la misma, que coincidirá, a su vez, con el ascenso de Pérez Jiménez al poder. La creciente industrialización, la profesionalización de la mano de obra petrolera, el incremento de las inversiones en esa dirección, la concentración de los capitales en negocios de importación y comercio, así como el crecimiento demográfico urbano, favorecieron la desruralización del país y el florecimiento de nuevos capitales medios antes inexistentes. Todo esto, que ya iba teniendo lugar en la dictadura de Pérez Jiménez, se irá transformando en un sector de ingresos medios, pero con creciente poder adquisitivo, de preferencias y estética urbana, de proyección profesional y ética democrática, cuya consolidación tendrá lugar, sin duda, dentro del modelo liberal y desde muy temprano. En síntesis, si en la primera mitad del siglo XX la riqueza nacional se distribuía entre sectores propietarios de grandes extensiones de tierra y unos pocos favorecidos por la explotación petrolera extranjera, luego del proceso mencionado se conformarán sectores que impulsarán la industrialización agraria, el capital comercial basado en la importación, las inversiones en la construcción, el desarrollo industrial, así como el capital financiero; y junto a todos ellos se desarrolló una clase política profesional de ethos democrático que será la plataforma para la consolidación del proyecto liberal. Estas variables permitieron el desarrollo de un sector de ingresos medios y gran poder adquisitivo que podemos llamar, desde luego, clase media.
} 
En ese sentido, el discurso revolucionario, siempre agresivo y radical, señaló a la moral 'burguesa' de la clase media como el espíritu mismo de los intereses norteamericanos. La ética liberal fue el centro de las acusaciones, y por ello resulta coherente con este discurso el haberse asociado con los mayores adversarios de tales intereses. Destruir el modelo derrotado no solo conducía al desplazamiento de sus agentes; esa acción encierra, asimismo, la cristalización subjetiva de una 'revancha social', una especie de consumación de los deseos de aquel malestar capitalizado ideológicamente.

La revolución garantizó el ocultamiento de su proyecto de captura de riquezas tras el velo seductor del discurso ideológico, especialmente condimentado por el magnetismo que producía la presencia de Chávez. La realidad subyacente a esta práctica política queda al desnudo, por ejemplo, cuando accedemos a los detalles de la trama construida para la explotación del circuito energético. Para lograr su cometido, la destrucción del modelo liberal debía ser absoluta: política, institucional, ideológica, pero sobre todo económica, al desbancar los intereses instaurados en beneficio de los nuevos. El modelo sustituto, como lo vimos, desarrolló estrategias opuestas al anterior, en correspondencia con lo desplegado ideológicamente. La revancha prometida llegaba así de forma alucinatoria a través del discurso socialista, mientras que el objetivo real era obtenido a través de la captura del Estado. La revolución fue el manto de opacidad que encubrió una realidad más concreta: la creación y el enriquecimiento de nuevas redes.

El nuevo modelo de enriquecimiento no resulta de una elección premeditada; es la totalización de una sumatoria de decisiones de poder, tanto por obtenerlo como por preservarlo. ${ }^{41}$ Es, precisamente, la

\footnotetext{
${ }^{41}$ La cartelización de los negocios evolucionó hacia otras áreas del Estado que no necesariamente representan una fuente de riqueza tradicional, sino que han sido transformadas en negocios cartelizados. El ejemplo más conspicuo se encuentra en la distribución y comercialización de alimentos como política pública. En tiempos de Chávez fue creado el Ministerio del Poder Popular para la Alimentación, y ese mismo año arrancó el Mercal (Mercados de Alimentos S.A.), una cadena de pequeños supermercados populares subsidiados cuyo objeto era "garantizar la seguridad alimentaria de las familias en situación vulnerable", como se indica en el decreto que lo sanciona (Decreto $\mathrm{N}^{\circ} 2.359$ del 9 de abril de 2003, en Gaceta Oficial No 37.672, 15 de abril de 2003). El fracaso de la 'misión' indujo a la expropiación de cadenas privadas de supermercados y al desarrollo de un plan aún mayor: PDVAL (PDVSA Alimentos), que creó una filial más a la empresa petrolera, cargándole la distribución masiva de alimentos. Alejadas la empresa
} 
materialización de relaciones de poder emergentes en detrimento de las derrotadas. El paso del tiempo evidenció, asimismo, que ese detrimento fue más allá, hasta alcanzar a toda la sociedad venezolana. La lógica de los carteles, como queda claro, no se detiene ante lo que destruye; su objetivo es el enriquecimiento. No obstante, en esa misma lógica, esto no se produce mediante reglas de juego de libre competencia, sino por medio de la eliminación de sus competidores. En el caso venezolano tiene lugar con la intervención del Estado: a través de leyes y decretos excluyentes, de la mano de la coerción que el monopolio de la violencia garantiza, por la vehiculización institucional de las transacciones, así como por el entramado de relaciones internacionales que se aseguran naturalmente con su investidura.

El viraje geoestratégico como resultado de las nuevas y necesarias sociedades internacionales condujo al despliegue de actitudes decisivas para la consecución de los negocios. Los flamantes aliados, asimismo, también persiguieron beneficios con esta relación. Rusia, China y Cuba, los socios de mayor peso en el proceso bolivariano, se aproximaron a Venezuela con objetivos claros, según cada una de sus agendas y necesidades. Independientemente de esos objetivos, ha quedado claro que la sociedad con el Estado venezolano ha favorecido esas agendas con solo observar el crecimiento del PIB en lo que va del siglo XXI, especial-

y la industria privada del acceso a las divisas por las drásticas políticas impuestas al respecto, Venezuela redujo su producción de alimentos a mínimos históricos, por lo que el Estado, para poder abastecer estos supermercados, recurrió a la importación: allí descansa el negocio, pues solo las redes dedicadas a la importación de alimentos con las instituciones públicas como base de operaciones son las que tienen acceso a las divisas y a las transacciones; el capital privado, es decir, los competidores, quedaron por fuera. La cartelización de la importación de alimentos, donde los programas Mercal y PDVAL fracasaron, impulsó la creación de un nuevo negocio: los Comités Locales de Abastecimiento y Producción Socialista, CLAP, que distribuyen las conocidas cajas de comida importada. El negocio se inició bajo el gobierno de Maduro en 2016, y comenzó importando alimentos desde México. Actualmente se distribuyen cientos de miles de estas cajas en todo el país, bajo un negocio que maneja millones de dólares administrados por redes instaladas en instituciones públicas, donde participan empresarios de otros países (Turquía, Argentina, Colombia). Las cajas son compradas a un costo que duplica su valor real, permitiendo el reparto del sobrante entre quien vende los alimentos y las redes que los adquieren en Venezuela. Cientos de miles de cajas al mes suman millones de dólares. Las cajas, por cierto, son vendidas en bolívares a la población 'favorecida', dinero que queda en manos de quienes las distribuyen directamente, los últimos agentes de las redes encargadas del caso. 
mente en el caso de rusos y chinos. ${ }^{42}$ Desde luego, tal crecimiento no es el resultado exclusivo de esta alianza, pero sin duda que con Venezuela fuera de la competencia por el mercado petrolero, la Federación de Rusia ha sacado provecho al asunto, por ejemplo. "Quizás el único enfoque analítico para ordenar esta complejidad consiste en una perspectiva de mercado" (Krauthausen 1994, 115).

Todo parece indicar, asimismo, que la destrucción de ciertas fuentes de riqueza en Venezuela, proceso que tiene lugar en beneficio de los carteles, favorece por otro lado a los nuevos socios internacionales. Su manifiesto interés por el apoyo a este proyecto político, incluso a la vuelta de la crisis padecida en los últimos años, da cuenta de algo más que solidaridad o proximidad ideológica. El interés, en todo caso, se mide por el provecho obtenido, y no a través de afectos o consideraciones. Es, igualmente, parte de un objetivo que está más allá de la camaradería política; la sociedad con Venezuela forma parte de las estrategias desplegadas por estas potencias para competir con Estados Unidos. En la destrucción del aparato productivo del país petrolero, los intereses norteamericanos tienen mucho que perder, y a esto parecen haber apuntado ambos contendores.

En correspondencia con la necesidad de desplazar antiguas sociedades y redes de capitales, la propuesta del socialismo venezolano apuntó hacia el "neoextractivismo en el contexto de un nuevo patrón global de acumulación del capital que presenta fundamentales desplazamientos geopolíticos", conscientes además de que esta estrategia "ha convertido al Sur de Asia, muy en particular a China, en el centro más

\footnotetext{
42 Para corroborar el crecimiento del PIB en Rusia y China durante el siglo XXI, ver Banco Mundial (2019). Parte de la política imperial que rusos y chinos han puesto en práctica durante el siglo XXI ha consistido en asociarse con 'países débiles' para establecer vínculos económicos que les favorezcan. A diferencia del imperialismo económico estadounidense, estas estrategias persiguen impedir el crecimiento de las economías asociadas, más allá de que el objetivo descanse en el desarrollo de las industrias extractivas, básicamente. Sobre la política china de asociaciones con "weaks states", ver Jeffrey Reeves (2015). Ambos imperios han crecido durante el siglo XXI, tal como la evolución de sus respectivos PIB lo indica, avanzando sobre regiones abandonadas o actualmente desprotegidas por los intereses norteamericanos, con especial énfasis en países donde fracasó el modelo de sustitución de importaciones, o donde resultaron catastróficas las abrasivas políticas de ajustes aplicadas a partir de 1989. Venezuela es un ejemplo del segundo caso, especialmente.
} 
dinámico de la acumulación global" (Lander 2014, 5). ${ }^{43}$ El neoextractivismo es, ciertamente, una forma de "reprimarización de las economías vinculada al incremento en la demanda de materias primas" procedente de potencias como China y Rusia (Merchand 2016, 157). No obstante, es también un modelo de desarrollo de estrategias macroeconómicas ortodoxas, basadas en la comercialización de minerales brutos, con sobreexplotación de los recursos naturales y efectos de degradación ambiental devastadores. Lejos de labrar una ruptura con el capitalismo que tanto adversa, el socialismo venezolano ha representado la continuidad, y sobre todo la profundización, de modelos abrasivos de explotación y agotamiento de los recursos naturales (García-Guadilla 2014). En este aspecto, la destrucción ha sido un resultado concreto e inocultable.

Las formas de explotación de la riqueza que han desplegado estas redes han enseñado, además, una lógica de depredación sin equilibrio; es decir, una desmesura en la captura de las riquezas capaz de agotar las fuentes sin el menor criterio de sostenibilidad. En ello se han llevado por delante a las fuentes — sí, como ha sido el caso de la industria petrolera o el circuito energético - pero también han dilapidado la posibilidad de convertir el privilegio de la explotación exclusiva en un bien hereditario, transgeneracional, con miras a futuro. En cambio, lo ejecutado da cuenta de una racionalidad primaria, apenas enfocada en la captura de la riqueza y su aprovechamiento inmediato, en crítica diferencia con la estructura familiar de las mafias italianas, centradas en el beneficio de varias generaciones. Aquí la eliminación de la competencia alcanzó a su propia descendencia.

La estructura de los carteles opera en jerarquías verticales sobre formas piramidales de organización. Las redes que lo integran constituyen grupos comprometidos por mecanismos de sujeción jerárquicos o por recompensas, cuya fidelidad no responde a solidaridades ni a doctrinas. Los jefes de carteles eventualmente coinciden con altos cargos públicos, de alto o bajo perfil, con responsabilidades de administración económica y política, así como de gerencia logística. Con la dilapidación de las fuentes de riqueza, la pérdida de eficiencia de las redes ocurre en forma invertida a su jerarquía, de abajo hacia arriba, angostando cada vez más el liderazgo y los mandos, profundizando la centralización del control y

${ }^{43}$ Así lo explica el sociólogo venezolano Edgardo Lander (2014), uno de los intelectuales más comprometidos con el proyecto de Chávez desde sus inicios, y defensor de sus propuestas aun en los peores años de su crisis. 
produciendo con ello más violencia, tanto hacia el interior del propio cartel, como hacia afuera. ${ }^{44}$ Esto sucede con relación directamente proporcional al agotamiento de la riqueza. El desgaste induce el incremento de la violencia en las operaciones y transacciones, y se observa igualmente en el trato hacia los competidores a través de estrategias excluyentes de mayor agresividad (con expropiaciones o invasiones a propiedades e infraestructuras productivas), así como en el vilipendio a los opositores políticos, arrinconados por entretejidos jurídicos que los inhabilitan o los enjuician. En correspondencia con estas acciones, el discurso ideológico, igualmente, se exacerba agudizando su radicalismo.

Los carteles venezolanos del siglo XXI entrecruzan lógicas de poder y lógicas de mercado (Krauthausen 1994, 112). No operan exclusivamente en un espacio $u$ otro; han articulado a ambos, en un movimiento que va desde el poder a la riqueza, y viceversa. En esto, la base militar del socialismo bolivariano ha jugado un rol categórico. No solo ha sido una sólida plataforma para sostener políticamente al chavismo, haciendo las veces de 'partido' sin depender de una estructura democrática, sino que además representa un recurso de defensa intimidante, y al mismo tiempo un control indisputable de los espacios donde tienen lugar los negocios (puertos, aduanas, fronteras, instituciones, industrias), en garantía de sus operaciones. Articulado con el cuerpo castrense, este socialismo se reserva el uso de la violencia como mecanismo simbólico

\footnotetext{
${ }^{44}$ En tiempos de altos ingresos petroleros, cuando el barril superaba los US\$100, el Estado desbordó sus instituciones de funcionarios fieles y comprometidos con el proyecto socialista, favorecidos con altos sueldos. El reparto de dinero a cambio de fidelidades políticas nunca significó un reparto de la riqueza, sino un mecanismo de sujeción más, un clientelismo consumado con efecto electoral; pero esto también se ejecutó sin criterios de sostenibilidad, y del mismo modo que sucedió con el circuito energético, las instituciones públicas perdieron la energía que se alimentaba de altos ingresos. La devaluación de la moneda, la hiperinflación, la escasez de alimentos y medicinas, todo suma al deterioro de la calidad de vida que ha impactado en esa masa de empleados públicos que representa la mayor cantidad del empleo nacional. Tal impacto supone un efecto estructural devastador en las funciones del Estado, pero también en la vida cotidiana de la sociedad. Los carteles solo pueden sostener su enriquecimiento, y eso es excluyente, incluso para los votos que les favorecen en el poder. En tiempos en los que el barril vale menos de la mitad que en la época de Chávez, los esfuerzos apuntan a mantener el poder para prolongar el acceso a la riqueza; el resto de las funciones públicas del Estado pierde su condición prioritaria y el desgaste consecuente pasa a formar parte de la destrucción concomitante que tiene lugar por la acción de los carteles. Esta situación ha contribuido directamente con la destrucción de la institucionalidad y la eficiencia del Estado, e incluso con el deterioro de las relaciones en la propia sociedad venezolana.
} 
y concreto a la vez, sin lugar a flexibilidades. La verticalidad del mando militar se mimetiza, a su vez, con la disciplina ideológica y se funde en la figuración de un poder omnipresente de la mano del Estado. La omnipresencia del Estado en esta Venezuela ha sido, además, un hecho constatable que resulta directamente proporcional a la ineficiencia de las instituciones públicas, solo eficaces para el resguardo de los negocios.

Al desplazar al pacto político que sostenía el orden anterior, los bolivarianos no conformaron estrictamente un nuevo pacto, sino que construyeron un entramado piramidal de jerarquías únicamente verticales asido a la autoridad del Estado y al poder que otorga el control excluyente de cada ámbito explotado. Un pacto político significa suscribir un acuerdo de intereses entre clases que toman decisiones. En el caso observado no hay pactos con otras clases; por el contrario, la cartelización del Estado ha significado la exclusión de la negociación con los competidores. En la doctrina antiliberal no puede haber espacio para la libre concurrencia al mercado ni para la amplitud participativa. No se toman decisiones en consenso con la competencia porque allí no hay lugar para intereses ajenos.

La crisis estructural del proyecto socialista en Venezuela, veinte años después de su puesta en marcha, parece el costo a pagar por las nuevas asociaciones estratégicas, pero fundamentalmente es el intercambio necesario que aseguró el enriquecimiento de las nuevas redes que hoy detentan el poder; es decir, a cambio de una riqueza sin competidores se ha perdido el país. Con ello se evidencia que tras el enmascaramiento de la revolución se esconden redes de corrupción y criminalidad, entramadas en la informalización de la institucionalidad como efecto relacional de la ética antiliberal. La cartelización del Estado es el resultado de un proceso político, pero también es la cristalización de un proyecto económico, con objetivos de enriquecimiento claramente definidos.

\section{CONCLUSIÓN}

El ascenso de Chávez al poder fue el resultado de un proceso social y político específicamente venezolano, vinculado a variables y problemas que se hicieron críticamente visibles en esa sociedad durante las dos últimas décadas del siglo XX. El proyecto socialista desarrollado posteriormente, no obstante, da cuenta de la materialización de ciertos intere- 
ses que se articulan internacionalmente, ya de forma regional como con alcances globales. Tal relación, cuyos objetivos trascienden lo ideológico o lo político, debe leerse igualmente en dos planos, tanto en lo local como en lo global. El proceso venezolano desplegado para articularse con estos objetivos de mayor alcance cristalizó en la transformación de la forma de hacer los negocios desde el Estado, cartelizando sus funciones y convirtiendo su espacio en una plataforma de enriquecimiento excluyente y de beneficios inmediatos, sin mayor proyección en el tiempo que hallarse asidos al poder. La experiencia específica de Venezuela, que enseña una depredación irreflexiva entramada en redes con perfiles de criminalidad y corrupción, no necesariamente es replicable en todos los contextos de la región.

El rostro más visible de ese proceso, sin embargo, ha sido su empaque ideológico socialista, un vehículo que ha producido sociedades regionales en América Latina de la mano de proyectos políticos con llamativa similitud, todos ellos desarrollados en el siglo XXI. El de Chávez, por cierto, fue el primero en alcanzar el poder en 1999. La propuesta socialista, ahora y siempre, representa la oposición crítica al modelo liberal, por lo que su despliegue conduce, sin duda, al desarrollo y cristalización de formas y estrategias diferentes en las funciones del poder, en la organización del Estado, en el uso de sus instituciones y, desde luego, en la circulación del capital. Por tanto, tales asociaciones regionales enhebradas con ese vehículo ideológico, a su vez, se entretejen globalmente a través de compromisos de mercado con potencias que compiten arduamente con los modelos liberales de enriquecimiento y organización política. El giro político que buena parte de América Latina ha dado recientemente, parece dejar claro que la democracia liberal, referente del bienestar social en el mundo occidental moderno, así como sus formas tradicionales de hacer circular el capital, se encuentran bajo amenaza.

Está claro que la cartelización de los negocios, como ha sucedido en Venezuela, no representa la única alternativa para desbancar al modelo liberal, y en este trabajo no nos hemos propuesto descifrar por qué se siguió este camino en Venezuela y no otro, sino comprender cómo se conformó esta decisión y cómo se desarrolló ese proceso. Pensamos que la calificación de cartel, que coincide con la forma en la que el Estado socialista ha ejecutado los negocios, remite igualmente a la moral delic- 
tiva de los carteles criminales entramados en empresas ilegales, pues ha quedado claro que, ante la situación crítica que presenta la sociedad venezolana, el gobierno bolivariano, o bien, las redes que lo conforman con esos objetivos, enseña una moral desprovista de empatía hacia el otro, igualando las prácticas de violencia literal con las que proceden los carteles criminales. Aquí el otro, además, no es únicamente el competidor a eliminar, sino la sociedad sobre la cual se encuentran anclados.

Por último, cabe preguntarse si, al igual que en las redes criminales de los carteles del narcotráfico, estas sociedades, redes y fidelidades conformadas en torno al enriquecimiento excluyente y depredador, conducen a sujeciones definitivas que imposibilitan su abandono y aseguran la permanencia a costa de su vida. Si esto funciona así dentro de los entramados nacionales de Venezuela, muy probablemente ha de funcionar de la misma manera hacia afuera, y el país petrolero ha de estar pagando un alto precio por la asociación con potencias y terceros que lo sujetan en su beneficio por encima de la vida de millones de personas.

\section{BIBLIOGRAFÍA}

Altez, R. 2012. Una categoría conceptual a la deriva: discusión sobre la aplicabilidad de 'revolución' a las independencias hispanoamericanas (39-80). En Vovelle, M., Chust, M. y Serrano, J.A. (eds.), Escarapelas y coronas: Las revoluciones continentales en América y Europa, 1776-1835. Caracas: Alfa.

Altez, R. 2015. Independencia-revolución: una sinonimia de largo efecto ideológico en América Latina (43-64). En Altez, R. y Chust, M. (eds.), Las revoluciones en el largo siglo XIX latinoamericano. Madrid: Iberoamericana-Vervuert.

Arenas, N. 2001. ¿Del populismo rentista al populismo neoliberal? Estudios Latinoamericanos $16,181-200$.

Asamblea Nacional 2017. Comisión mixta para el estudio de la crisis eléctrica. Informe Final. Asamblea Nacional, 15 de enero.

Banco Mundial 2019. Disponible en: https://datos.bancomundial.org/indicador/ NY.GDP.PCAP.CN?locations=NL\&name_desc=false [14 de junio 2019].

Briceño-León, R. 2015. Violencia urbana, sistema normativo y democracia en Venezuela (205-236). En Gómez, M.A. y Pérez Perdomo, R. (eds.), Cultura jurídica y políticas en Venezuela revolucionaria (1999-2013). Caracas: Academia de Ciencias Políticas y Sociales.

Cánova, A., Herrer, L.A., Rodríguez, R.E. y Graterol, G. 2014. El TSJ al servicio de la revolución: la toma, los números y los criterios del TSJ venezolano (20042013). Caracas: Galipán. 
Carrión, F. y Pinto, J.P. 2017. La cartelización en América Latina. Presencia 33, 82-88.

Centro Nacional de Gestión del Sistema Eléctrico 2008. Informe Anual. Resumen Ejecutivo. Disponible en: http://www.opsis.org.ve [9 de mayo 2019].

Cipolla, C.M. 1999. La odisea de la plata española. Conquistadores, piratas y mercaderes. Barcelona: Crítica.

Consejo de la Facultad de Ciencias Económicas y Sociales de la Universidad Central de Venezuela 2019. Pronunciamiento del Consejo de la Facultad de Ciencias Económicas y Sociales ante la agresión a la comunidad indígena de los pemones. Documento de circulación pública. Suscrito el 28 de febrero.

Coronil, F. 2002. El Estado mágico. Naturaleza, dinero y modernidad en Venezuela. Caracas: Nueva Sociedad.

Corpoelec 2013. Venezuela declara en emergencia su sistema eléctrico para estabilizarlo. La Nación [23 de abril]. Disponible en: https://www.nacion. com/el-mundo/venezuela-declara-en-emergencia-su-sistema-electrico-paraestabilizarlo/M24KIVPDDFCFJPT5KUFWNUDBN4/story/ [4 de junio 2019].

Corpoelec 2016. Venezuela ocupa el primer lugar en consumo de energía per cápita de América Latina [22 de junio]. Disponible en: www.corpoelec.gob.ve/ noticias/ [29 de abril 2019].

Corrales, J. y Penfold, M. 2012. Un dragón en el trópico. Caracas: La Hoja del Norte.

Dombois, R. 1998. Dilemas organizacionales de las economías ilegales. Análisis Político 33, 14-29.

Gaceta Oficial de Venezuela 2003. № 37.672, 15 de abril.

Gaceta Oficial de Venezuela 2007. $N^{\circ} 38.736,31$ de julio.

Gaceta Oficial de Venezuela 2009. $N^{\circ} 39.298,3$ de noviembre.

Gaceta Oficial de Venezuela 2010. ํㅜ 39.345, 13 de enero.

Gaceta Oficial de Venezuela 2010. $\mathrm{N}^{\circ} 39.363,8$ de febrero.

Gaceta Oficial de Venezuela 2013. № 40.151, 22 de abril.

García-Guadilla, M.P. 2014. Dilemas del ecosocialismo post-neoliberal y resistencia de los movimientos sociales frente al modelo neo-extractivista en Venezuela. Encuentros Latinoamericanos 8(2), 3-47.

Hernández, N. 2018. Contexto actual de la energía en Venezuela. Informe especial. Caracas: La Patilla.

Hoevel, C. y Mascareño, A. 2016. La emergencia de las redes clientelares en América Latina: Una perspectiva teórica. Revista Mad 34, 36-64. Disponible en: http://dx.doi.org/10.5354/0718-0527.2016.40612 [19 de abril 2019].

Krauthausen, C. 1994. Poder y mercado. El narcotráfico colombiano y la mafia italiana. Nueva Sociedad 130, 112-125.

Lander, E. 2014. El neoextractivismo como modelo de desarrollo en América Latina y sus contradicciones. Berlín: Heinrich Böll Stiftung. 
López-González, A. 2018. La crisis del sistema eléctrico venezolano, sus causas reales y alternativas sustentables para su superación. Observatorio de Ecología Política de Venezuela. Disponible en: www.ecopoliticavenezuela.org [5 de junio 2019].

López-González, A. 2019. El Black-Out del sistema eléctrico venezolano: ruptura del equilibrio en la generación termoeléctrica. Observatorio de Ecología Política de Venezuela. Disponible en: www.ecopoliticavenezuela.org [5 de junio 2019].

López Maya, M. 2005. Del viernes negro al referendo revocatorio. Caracas: Alfa.

Mascareño, A., Stamford da Silva, A., Loewe, D. y Rodríguez, D. 2016. Redes informales e instituciones democráticas en América Latina. Dados 59(3), 683718 .

Merchand Rojas, M.A. 2016. Neoextractivismo y conflictos ambientales en América Latina. Espiral 23(66), 155-192.

Palacio, M. y Serrano, S. 2010. Colombia y México. Las violencias del narcotráfico (104-154). En Alvarado, A. y Serrano, M. (coords.), Los grandes problemas de México. Seguridad nacional y seguridad interior. México DF: El Colegio de México.

PDVSA 2006. Arrancó la Misión Revolución Energética [17 de noviembre]. Disponible en: http://www.pdvsa.com/index.php?option=com_content\&view=arti cle\&id=1863:3254\&catid=10\&Itemid=589\&lang=es [12 de mayo 2019].

Peña, D., Rodríguez, C., Solana, P. y Portela, J. 2013. Detección de riesgos operacionales en empresas del sector eléctrico aplicando las recomendaciones del Comité de Basilea. Interciencia 38(11), 777-784.

Ramos, J. 1997. Un balance de las reformas estructurales neoliberales en América Latina. Revista de la CEPAL 62, 15-38.

Reeves, J. 2015. Chinese Foreign Relations with Weak Peripheral States: Asymmetrical Economic Power and Insecurity. New York: Routledge.

Romero, A. 1994. Decadencia y crisis de la democracia. ¿Adónde va la democracia venezolana? Caracas: Panapo.

Saturno, S. y Sánchez, M. 2019. Venezuela en apagón. Desinversión, falta de mantenimiento y desfalco. Caracas: Transparencia Venezuela.

Sistema Bolivariano de Información y Comunicación [12 de enero]. Inaugurada Planta de Generación Distribuida Las Hernández I (2010). Disponible en: http://www.alopresidente.gob.ve/info/6/1592/inaugurada_planta_de.html [29 de abril 2019].

Urdaneta, G., Scrofina, J.S. y Grisanti, J. 2009. Venezuela. La energía en cifras, 2008-2009. Caracas: Instituto de Estudios Superiores en Administración.

Vásquez, P. 2019. Pays hors service. Paris: Buchet Castel.

Villegas, A., Aller, J., De Oliveira, P., Martínez, M., Díaz, H., Salazar, L., Molina J. y González, M. 2010. La USB ante la crisis del sector eléctrico venezolano. Caracas: Universidad Simón Bolívar. EP 